\title{
A statistical mechanistic approach including temperature and salinity effects to improve salmon lice modelling of infestation pressure
}

\author{
Leif Christian Stige*, Kari O. Helgesen, Hildegunn Viljugrein, Lars Qviller
}

Norwegian Veterinary Institute, 1431 Ås, Norway

\begin{abstract}
Salmon lice Lepeophtheirus salmonis pose a major threat to the sustainable development of salmonid farming. To investigate effects of farm-origin salmon lice on wild salmonids, salmon lice dynamics are typically simulated using models that depend on experimentally determined rates of development, reproduction, mortality and infestation. Several recent studies provide new estimates of how these demographic rates depend on temperature and salinity. Here, we review and synthesize these studies and test if updating a salmon lice infestation model based on the new insights improves predictions of salmon lice infestations on salmon post-smolts in experimental cages in the sea. This model predicts spatiotemporal variation in infestation pressure based on weekly monitoring data of salmon lice and sea temperature in all salmonid fish farms in Norway, here supplemented by temperature and salinity data from a regional ocean model. Using data from 2012-2017 to select model formulation, we found the largest improvement in explanatory power by incorporating a salinity-dependent infestation rate. Updating functions for temperaturedependent egg production and infestation rates led to smaller improvements. Moreover, results suggest additional effects of temperature and a possible temperature-salinity interaction effect, not captured by the modelled processes. Out-of-sample predictions for experimental cage data from 2018-2020 confirmed that the uncertainty was realistically quantified, but also showed that associations of salmon lice infestations with salinity and temperature had changed. These results provide a field evaluation of experimental data and point to a knowledge gap regarding the combined effects of temperature and salinity on salmon lice infestations.
\end{abstract}

KEY WORDS: Salmon lice dynamics - Spatiotemporal modelling - Egg production rate . Development time $\cdot$ Dispersal $\cdot$ Infestation rate

\section{INTRODUCTION}

The salmon louse Lepeophtheirus salmonis is a parasitic copepod on salmonid fish and the dominant sea louse species on farmed salmonids in the Northern Hemisphere (Pike \& Wadsworth 1999). The parasitic stages of $L$. salmonis live on the skin of the host fish and disperse by means of planktonic larval stages (Pike \& Wadsworth 1999). The lice larvae hatch from egg strings that normally remain attached to the female during development (although if stressed, the

\footnotetext{
${ }^{*}$ Corresponding author: leif.christian.stige@vetinst.no
}

egg strings may become detached and disperse as well; Eisenhauer et al. 2020). High farm density locally leads to high lice density with potentially adverse effects on fish welfare and survival (Grimnes \& Jakobsen 1996). As a consequence, salmon lice are a density-dependent constraint to salmonid farming (Jansen et al. 2012, Kristoffersen et al. 2014). Salmon lice of farm origin also cause increased mortality of wild salmonids, such as salmon post-smolts, which migrate through coastal areas with high farm densities (Krkošek et al. 2009, Vollset et al. 2018), and sea

() The authors 2021. Open Access under Creative Commons by Attribution Licence. Use, distribution and reproduction are unrestricted. Authors and original publication must be credited. 
trout Salmo trutta, which remain in coastal waters during their marine phase (Thorstad et al. 2015). For salmonid farming to be sustainably managed, we need quantitative knowledge about how salmon lice spread within and between farms and from farms to wild fish under different environmental conditions and production regimes.

Norway is the largest producer of Atlantic salmon $S$. salar and one of the largest producers of rainbow trout Oncorhynchus mykiss in the world (FAO 2019). The political ambition is to increase production further, conditional on the growth being environmentally sustainable (Ministry of Trade, Industry and Fisheries 2015). The environmental indicator used to regulate whether to increase, maintain or reduce production in different areas along the coast is the estimated detrimental effect that salmon lice from fish farms has on wild salmonids, with a main focus on the mortality of wild salmon post-smolts. To monitor salmon lice, fish farmers are required to count and report salmon lice on a weekly basis (Ministry of Trade, Industry and Fisheries 2012; monthly reporting before 2012). Statistical analyses of these data have provided insights into salmon lice dispersal and population dynamics (Jansen et al. 2012, Aldrin et al. 2013, Kristoffersen et al. 2014, Aldrin et al. 2019). The monitoring data are also key input data in models that have been developed to estimate the effects of farmorigin salmon lice on the mortality of salmon postsmolts (Kristoffersen et al. 2018, Myksvoll et al. 2018, Sandvik et al. 2020). The post-smolt mortality estimates from these models are updated regularly as part of the decision support for the government's regulation of fish farm production in Norway (e.g. Vollset et al. 2019). Considerable uncertainties in the mortality effects complicate interpretation and decision-making, however, and require a continual effort to improve the precision of the estimates.

Several studies in recent years have provided new information about production, mortality and infectivity of larval salmon lice, which can potentially improve the epidemiological modelling (reviewed by Brooker et al. 2018). For example, new experimental studies have been published on how temperature influences L. salmonis egg and larval development rates (Samsing et al. 2016, Hamre et al. 2019) and egg batch size (Samsing et al. 2016). New estimates have also been published on how the dispersal probability of $L$. salmonis larvae decreases with distance (Aldrin et al. 2019) and on the mortality rates of $L$. salmonis adults and larvae (Aldrin et al. 2017). Furthermore, experimental studies have provided new insights into how temperature and salinity influence mortality rates and the ability of lice larvae to successfully attach to a fish host (infectivity). The infectivity of L. salmonis larvae on Atlantic salmon post-smolts appears to be higher at around $10-15^{\circ} \mathrm{C}$ than at either higher or lower temperatures (Tucker et al. 2000, Samsing et al. 2016, Dalvin et al. 2020, Skern-Mauritzen et al. 2020). Low salinity has been associated with reduced hatching success of L. salmonis larvae (Johnson \& Albright 1991, Gravil 1996), reduced larval survival (Gravil 1996, Bricknell et al. 2006), reduced infectivity (Tucker et al. 2000, Bricknell et al. 2006) and larval avoidance of low-saline surface waters (Bricknell et al. 2006, Crosbie et al. 2019). Application of these results in epidemiological modelling is, however, complicated by the fact that vital rates such as mortality and infectivity are influenced by a number of abiotic and biotic factors that are difficult to represent realistically under laboratory settings (Brooker et al. 2018). Temperature and salinity may, therefore, scale differently with these rates in the sea than in the laboratory, and it is not certain that accounting for more processes in the epidemiological models improves predictions. Thus, there is a need for a systematic evaluation of which alterations in model settings actually improve predictions of salmon lice infestations on salmonids in the sea.

The aim of this study was to review and synthesize new results on salmon lice mortality, development, egg production and infestation rates and test if the precision of the estimates of salmon lice infestations on Atlantic salmon post-smolts could be improved by incorporating these new results. We considered the salmon lice infestation model by Kristoffersen et al. (2018) as a baseline model. This model predicts spatiotemporal variation in salmon lice infestation pressure based on monitoring data of salmon lice and temperature at fish farms as well as knowledge about salmon lice biology (following Kristoffersen et al. 2014). As farmed salmon outnumber wild salmonids by 2 orders of magnitude along the Norwegian coast (Heuch \& Mo 2001, Johansen et al. 2011), we assumed that salmon lice larvae were predominantly of farm origin; the fish farm monitoring data then provide extensive information about the spatial and temporal variation in the production of salmon lice larvae. The fish farm monitoring data also provide information about the rate at which salmon lice larvae infest new salmon hosts; however, the interpretation of these data is complicated by the anti-lice actions taken by the fish farmers, such as use of cleaner fish, shielding skirts, submerged feeding, functional feeds, etc. The infestation by salmon lice on Atlantic salmon postsmolts has therefore been determined by a number of sentinel cage experiments from 2012-2020 (Bjørn 
et al. 2011, Sandvik et al. 2020), which Kristoffersen et al. (2018) used to analyse infestation level as a function of infestation pressure.

Kristoffersen et al. (2018) provided a statistically robust model framework to test hypotheses about the biological and physical mechanisms that link the data on salmon lice larvae production and infestation. We used this model framework to test 12 hypotheses (H1-H12) for how predictions of salmon lice infestation could be improved compared to the baseline model. Each hypothesis represented a possible alteration of the baseline model by relaxing simplifications made in that model (H1, H4), updating parameter values for key processes in the model based on recent studies (H2, H3, H5, H6), accounting for temperature and/or salinity effects on processes previously assumed to be constant (H7-H11) or statistically estimating temperature and salinity effects (H12). To address hypotheses about effects of temperature at infestation time and salinity (H9-H12), the measured farm temperatures were supplemented by temperature and salinity data from a regional ocean model (Asplin et al. 2020). The hypotheses were that predictions of salmon lice abundance on salmon post-smolts in sentinel cage experiments would become more precise by:

(H1) calculating infestation pressure based on the cumulative number of infective larvae in the experimental period (new methodological approach) instead of the production of infective larvae during the last 2 wk of the cage experiment (baseline model);

(H2) using new (Aldrin et al. 2019) instead of old (Aldrin et al. 2013) estimates for how the dispersal probability of salmon lice larvae decreases with distance from the farm that the larvae originated from; (H3) testing alternative mortality rates of adult (eggbearing) female lice, planktonic and parasitic lice larvae (Stien et al. 2005, Aldrin et al. 2017);

(H4) calculating development times by a temperaturedependent development fraction approach (Hamre et al. 2019) instead of using a degree-days approximation (Kristoffersen et al. 2018);

(H5) updating the function for temperature-dependent egg development time (Stien et al. 2005) with new experimental data (Samsing et al. 2016, Hamre et al. 2019);

(H6) updating the function for temperature-dependent larval development time (Stien et al. 2005) with new experimental data (Samsing et al. 2016) or replacing it by a newly published function (Samsing et al. 2016); (H7) replacing constant egg batch size and egg viability (Stien et al. 2005) with temperature-dependent egg batch size (Samsing et al. 2016);
(H8) accounting for temperature-dependent egg viability (Samsing et al. 2016);

(H9) accounting for temperature-dependent infectivity (Tucker et al. 2000, Samsing et al. 2016, Dalvin et al. 2020, Skern-Mauritzen et al. 2020) or temperatureand time-dependent infectivity (Skern-Mauritzen et al. 2020);

(H10) accounting for salinity-dependent egg viability (Johnson \& Albright 1991);

(H11) accounting for salinity-dependent infectivity (Tucker et al. 2000, Bricknell et al. 2006); and

(H12) statistically estimating effects of sea temperature and salinity on lice abundance that operate through, e.g. mortality rates of lice larvae.

These hypotheses are also relevant for other models of salmon lice dynamics, and results contribute to improve our understanding of salmon lice biology.

\section{MATERIALS AND METHODS}

\subsection{Data}

Extensive monitoring data from the aquaculture industry provided information about the spatiotemporal variation in the production of newly hatched salmon lice of farm origin. All active marine salmonid farms in Norway are required to count and report salmon lice Lepeophtheirus salmonis infestations, and also to report farm numbers of fish, the geographic coordinates of the farm and water temperature at $3 \mathrm{~m}$ depth (as described by Jansen et al. 2012, Kristoffersen et al. 2014). We used data from January 2012 to July 2020, comprising on average 608 active salmonid (Atlantic salmon and rainbow trout) farms at any given time (Fig. 1). The lice and temperature data have weekly resolution and are publicly available at the BarentsWatch portal (https://www.barents watch.no/en/fishhealth/). The salmonid production data have monthly resolution and are administered by the Directorate of Fisheries. The monthly and weekly data were matched and converted to a daily time scale as described by Kristoffersen et al. (2018).

Counts of salmon lice on salmon post-smolts placed in sentinel cages along the Norwegian coast (Fig. 1) provided information about the spatiotemporal variation in infestation rate (see Bjørn et al. 2011, Sandvik et al. 2020 for information about experimental setup). Each year from 2012-2020, between 49 and 206 (mean 117) sentinel cages were placed in the sea for periods of between 6 and 30 (mean 17) days in May-August. The cages were $0.9 \mathrm{~m}$ wide, $0.8 \mathrm{~m}$ high and deployed at $0.5 \mathrm{~m}$ depth. Each cage contained 


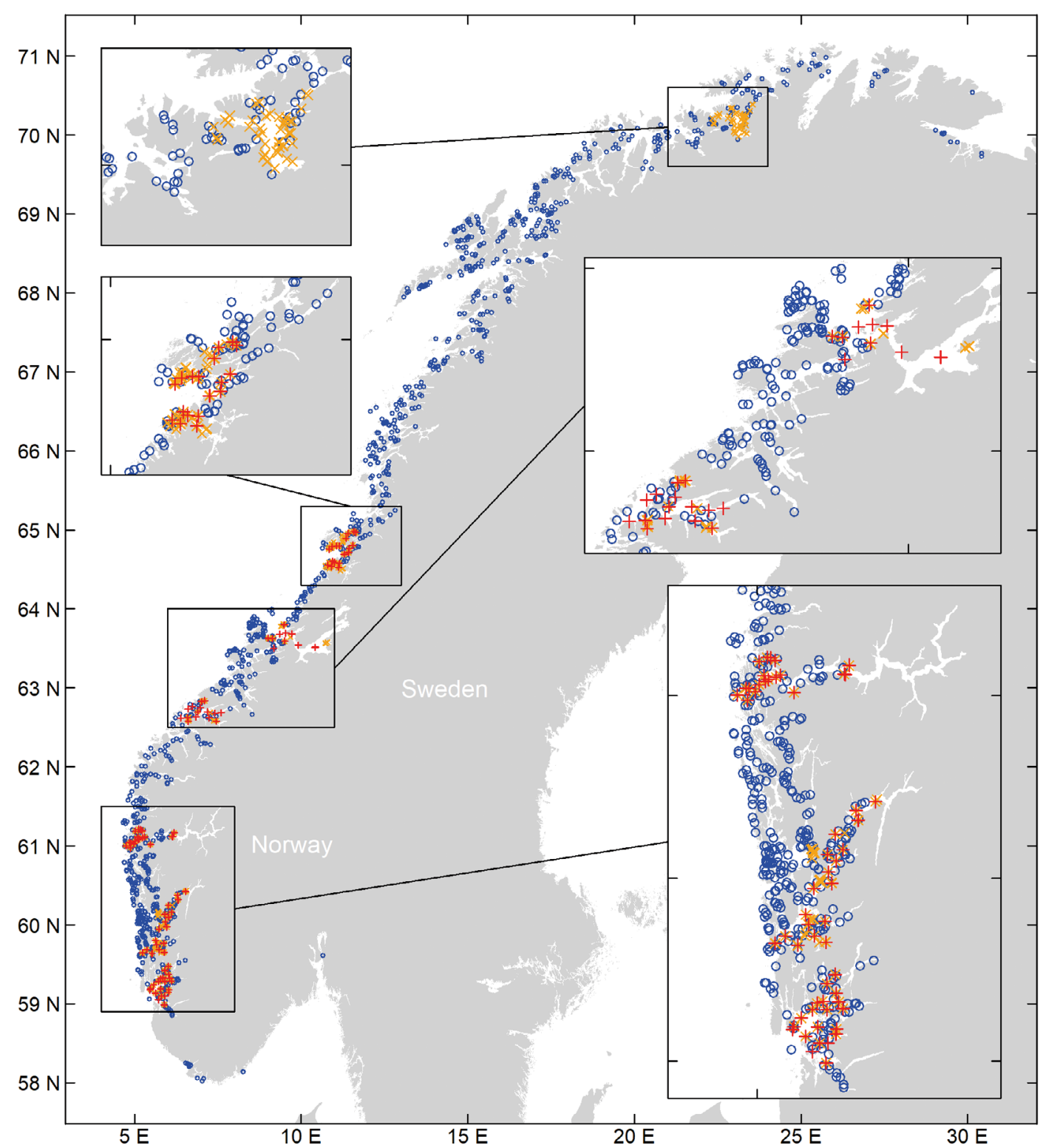

Fig. 1. Locations of sentinel cages in 2012-2017 (orange tilted crosses) and 2018-2020 (red crosses) and active salmonid farms in Norway during the study period (blue circles)

around 25 farm-reared salmon post-smolts that were louse-free at the start of the experiments. The fish were around $20 \mathrm{~cm}$ long, with annual averages between 19 and $22 \mathrm{~cm}$ and individual lengths between 8 and $31 \mathrm{~cm}$ (measured for a representative subset of the fish; data lacking for 2016 and 2017, and annual averages about $2 \mathrm{~cm}$ longer in 2018-2020 than 2012-2015). We used data on total salmon lice abundance (all parasitic stages) per fish at the end of the experiments. These data are publicly available through the Norwegian Marine Data Centre (www. nmdc.no; data for 2019 and 2020 provided to us by Ørjan Karlsen, Institute of Marine Research).
Spatiotemporal variation in sea surface salinity and temperature at $3 \mathrm{~m}$ depth were estimated from the 'NorKyst800' hydrodynamic ocean model, which is also used in an operational model system for salmon lice monitoring by the Institute of Marine Research (Asplin et al. 2020). We used data from a hindcast model run that included interannual, seasonal and geographic variation in freshwater runoff from land. Freshwater runoff until September 2017 was obtained from the 'HBV' hydrology model of the Norwegian Water Resources and Energy Directorate (Beldring et al. 2003). Freshwater runoff after that date was calculated based on station data 
(J. Albretsen pers. comm.). We extracted daily salinity and temperature values for the $800 \mathrm{~m}$ model grid-cell coordinate nearest each sentinel cage or farm.

In the subsequent analyses, we used reported temperatures and NorKyst800-modelled salinities for farm locations and NorKyst800-modelled temperatures and salinities for sentinel cage locations. The NorKyst800 model captures variations in temperature and salinity in coastal waters quite well, with the deviation typically being within a unit of salinity and $1^{\circ} \mathrm{C}$ of temperature (Dalsøren et al. 2020). A supplementary analysis confirmed that NorKyst800-modelled temperature and salinity values were generally consistent with temperatures reported for farm locations and temperature and salinity measured at a subset of the sentinel cages, although regional and short-term deviations occurred (see the Supplement at www.int-res.com/ articles/suppl/q013p339_supp.pdf for details). We extracted NorKyst800-modelled temperature at $3 \mathrm{~m}$ to be able to compare with reported farm temperatures, but note that especially in freshwater-stratified inner parts of fjords, temperatures around sentinel cages (around $1 \mathrm{~m}$ ) may be higher or lower. Salinity at sea surface typically represents the lowest salinity in the water column and a lower limit of the ambient salinity experienced by the salmon lice. Note that no fixed depth can fully represent the ambient environment of attached and pelagic salmon louse stages, as both fish hosts and pelagic salmon lice larvae can potentially adjust their vertical positioning in response to environmental changes (e.g. Oppedal et al. 2011, Crosbie et al. 2019, 2020).

\subsection{Outline of analysis}

We first used sentinel cage data from 2012-2017 to improve the explanatory power of the salmon lice model, comparing alternative methods to calculate infestation pressure at the cage locations, alternative distance functions for the spread of salmon lice from fish farms, alternative mortality rates, alternative functions for temperature-dependent development rates and alternative functions for temperature- and salinity-dependent egg production and infestation rates. We then assessed if temperature and salinity could explain some of the unexplained variation; for example, through temperature and salinity effects on lice mortality. The out-of-sample predictive power of the selected model was assessed using sentinel cage data from 2018-2020.

\subsection{Salmon lice infestation model}

The salmon lice infestation model we used as a baseline model was described in detail in Kristoffersen et al. (2014) and Kristoffersen et al. (2018). The purpose of the model was to assess how salmon lice from salmonid farms influence the survival of wild salmon post-smolts. We investigated the 2 first steps in the model: that is, firstly, the estimation of spatial and temporal variation in concentrations of infective salmon lice larvae in the sea (hereafter termed 'infestation pressure'), and secondly, the estimation of the abundance of parasitic salmon lice on salmon postsmolts exposed to a given infestation pressure.

The daily recruitment of newly hatched infectious salmon lice larvae to a geographic position $i$ at time $T$, termed $N_{i, T}^{R}$, was calculated by summing the product of egg production, successful development, survival and dispersal across all potentially contributing farms $j=1, \ldots, n j$ and daily time steps $t=t 0, \ldots, T$, with t0 = 1 January 2012:

$$
N_{i, T}^{R}=\sum_{j=1}^{n j} \sum_{t=t 0}^{T}\left(N_{j, t}^{E} \cdot S_{j, t, T} \cdot r_{i, j}\right)
$$

Specifically, $N_{j, t}^{E}$ was the number of salmon lice eggs produced from fish at farm $j$ and day $t, s_{j, t, T}$ was the fraction of these eggs that survived and developed into the infectious larval stage from time $t$ to $T$ and $r_{i, j}$ was the probability of dispersal of larvae from farm $j$ to location $i$.

\subsubsection{Salmon lice eggs produced per farm per day}

The daily number of eggs produced $\left(N_{j, t}^{E}\right.$ in Eq. 1a) was calculated by multiplying the total number of adult female salmon lice $\left(N_{j, t}^{A F}\right)$ with the number of eggs per egg batch $\left(B_{j, t}\right)$ divided by the number of days between egg batches, which was approximated by the egg development time to hatching $\left(D_{j, t}^{E}\right)$ :

$$
N_{j, t}^{E}=D_{j, t}^{A F} \cdot B_{j, t} / D_{j, t}^{E}
$$

The total number of reproductive female salmon lice $\left(N_{j, t}^{A F}\right)$ was calculated by multiplying the reported mean number of adult female lice per fish with the number of fish at the farm.

In the baseline model, we assumed that each egg batch consisted of 2 egg strings with 150 viable eggs in each string, independent of temperature and salinity (Stien et al. 2005, Kristoffersen et al. 2018):

$$
B_{j, t}=2 \cdot 150 \text { eggs }
$$

The time (days) between egg batches depended on sea temperature reported at the farm $\left(\operatorname{Temp}_{j, t}\right)$, fol- 
lowing experimentally derived minimum egg development times to hatching (Stien et al. 2005, Kristoffersen et al. 2018):

$$
D_{j, t}^{E}=\left(41.98 /\left[\text { Temp }_{j, t}-10+41.98 \cdot 0.338\right]\right)^{2} \text { days }
$$

\subsubsection{Survival and development of eggs to infectious stage}

The fraction of eggs that survived and developed into the infectious larval stage from time $t$ to $T\left(s_{j, t, T}\right.$ in Eq. 1a) was a function of egg development time to hatching $\left(D_{j, t}^{E}\right)$, larval development time from hatching to infectious stage $\left(D_{j, t}^{L}\right)$, daily mortality rate of females with developing eggs attached $\left(M^{E}\right)$ and daily mortality rate of larvae $\left(M^{L}\right)$ :

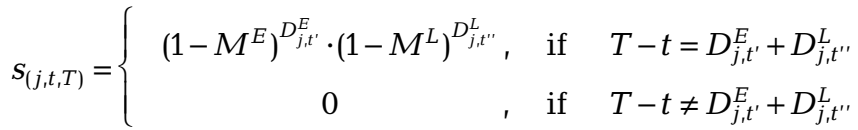

The 'if'-statement in the equation ensured that the fraction was only non-zero if the number of days from $t$ to $T$ equalled the development times of eggs to infectious larvae (as an integer number). This step implied that we only counted the larvae the day they entered into the infective stage, and that we calculated infestation pressure as the number of infective larvae produced in a given period. The fraction of eggs surviving to the infective stage was the product of the daily stage-dependent survival values (1 minus mortality) from time $t$ to $T$. In the baseline model, we assumed that the mortality rates of eggs and larvae were identical: $M^{E}=M^{L}=0.17$ (Kristoffersen et al. 2018). The notations $t^{\prime}$ and $t^{\prime \prime}$ referred, respectively, to the successive time intervals for the egg and larval stages, for eggs starting to develop at time $t$. The development times depended on the temperatures reported at the farm from time $t$ onwards $\left(\right.$ Temp $_{j, t}$ $\left.T e m p_{j, t+1}, T e m p_{j, t+2}, \ldots\right)$. In the baseline model, we assumed that egg and larval development required 126 degree-days (Kristoffersen et al. 2018). That is, we found the lowest value of the sum of egg and larval development times $\left(D_{j, t^{\prime}}^{E}+D_{j, t^{\prime \prime}}^{L}\right)$ that satisfied:

$$
\begin{aligned}
& \operatorname{Sum}\left(\operatorname{Temp}_{j, t}, \operatorname{Temp}_{j, t+1}, \operatorname{Temp}_{j, t+2}, \ldots, \operatorname{Temp}_{\left.j, t+D_{j, t^{+}}^{E}+D_{j, t^{\prime \prime}}^{L}\right)}(6)\right. \\
& \geq 126 \text { degree-days }
\end{aligned}
$$

\subsubsection{Dispersal of salmon lice from farms}

The probability of dispersal of larvae from farm $j$ to geographic position $i$ ( $r_{i, j}$ in Eq. 1a) was a function of the seaway distance, $d_{i, j}(\mathrm{~km})$, from farm $j$ to geo- graphic position $i$ (Aldrin et al. 2013, Kristoffersen et al. 2018):

$$
r_{i, j}=\frac{\exp \left(-1.444-0.351\left[d_{i, j}^{0.57}-1\right] / 0.57\right)}{\exp (-1.444-0.351[0-1] / 0.57)}
$$

The dispersal probability was set to zero for distances larger than $200 \mathrm{~km}$. This function shows how the concentration of infective salmon lice larvae decreases as a function of distance from each farm of origin.

\subsubsection{Infestation pressure at sentinel cage locations}

In the baseline model, infestation pressure at a sentinel cage experiment conducted at geographic position $i$ and time $T^{\prime}$ was calculated as the total recruitment $\left(T R_{i, T^{\prime}}\right)$ of newly hatched infectious salmon lice larvae $\left(N_{i, T}^{R}\right.$ in Eq. 1a) during the last 2 calendar weeks of the experiment (Kristoffersen et al. 2018):

$$
T R_{i, T^{\prime}}=\sum_{T} N_{i, T}^{R}
$$

A mixed-effects model with negative binomial error structure analysed salmon lice counts on salmon post-smolts as a function of infestation pressure:

$N_{k, i, T^{\prime}}^{\text {Obs }} \sim \exp \left[\beta_{0}+\beta_{1} \ln \left(T R_{i, T^{\prime}}\right)+\ln \left(\right.\right.$ Duration $\left.\left._{i, T^{\prime}}\right)+b_{i, T^{\prime}}+C_{i, T^{\prime}}\right]$

Here, $N_{k, i, T^{\prime}}^{O b s}$ referred to observed counts of salmon lice on fish $k$ in a sentinel cage experiment at position $i$ and time $T^{\prime}, \beta_{0}$ was the intercept, $\beta_{1}$ quantified the relationship with the calculated infestation pressure, the offset variable 'duration' was the duration of the experiment (days), $b_{i, T^{\prime}}$ was a random effect of the combination of area (among 7 fjord systems; Fig. 1), year $(2012, \ldots, 2017)$ and time period (early or late summer) of the experiment and $C_{i, T^{\prime}}$ was a random effect of cage nested in area-cage-period (modified from Kristoffersen et al. 2018). We assumed that the random effects of area-year-period and cage were normally distributed with means zero and standard deviations $\sigma_{1}$ and $\sigma_{2}$, respectively. The shape of the negative binomial distribution depends on the estimated dispersion parameter $\theta$, and the variance is $\mu+$ $\mu^{2} / \theta$, where $\mu$ is the mean.

\subsection{Alternative model formulations}

2.4.1. Infestation pressure calculated as cumulative number of infective larvae (H1)

As an alternative to calculating infestation pressure as total recruitment $\left(T R_{i, T^{\prime}}\right.$ in Eq. 8a) of newly 
hatched infectious salmon lice larvae during the last 2 wk of the experiment, we calculated infestation pressure as total number of infective larvae $\left(T I_{i, T^{\prime}}\right)$ accumulated during the experiment:

$$
T I_{i, T^{\prime}}=\sum_{T} N_{i, T}^{I} \cdot\left(1-M^{C}\right)^{T^{\prime}-T}
$$

Here, $T I_{i, T^{\prime}}$ referred to infestation pressure for a sentinel cage experiment at geographic position $i$ that ended at day $T^{\prime}, N_{i, T}^{I}$ was the number of infective larvae at any given time $T$ of the experiment and $M^{C}$ was the daily mortality of larvae that had successfully attached to a fish. The sum was calculated from the start day ( $T=T^{\prime}-$ Duration) to the end day $\left(T^{\prime}\right)$ of the experiment. We used $M^{C}=0.001$ based on mortality estimates for chalimus stages of $L$. salmonis by Aldrin et al. (2017) derived from statistical analysis of monitoring data from Norwegian fish farms. The number of infective larvae at Day $T$ was calculated by modifying Eqs. (1a) \& (5a):

$$
\begin{aligned}
& N_{i, T}^{I}=\sum_{j=1}^{n j} \sum_{t=t 0}^{T}\left(N_{j, t}^{E} \cdot s^{\prime}{ }_{j, t, T} \cdot r_{i, j}\right)
\end{aligned}
$$

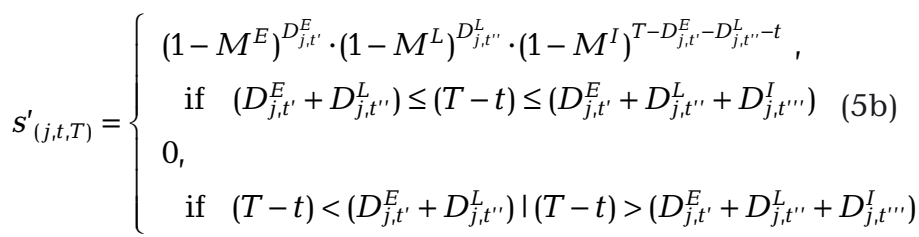

Here, $s_{j, t, T}^{\prime}$ in Eq. (1b) was the fraction of eggs that had developed into, and remained in, the infective larval stage. The fraction $s_{j, t, T}^{\prime}$ was defined by Eq. (5b). The 'if'-statement in Eq. (5b) ensured that the fraction was only non-zero if eggs produced at time $t$ were in the infective larval stage at time $T$. When this condition was met, the fraction surviving was the product of the daily stage-dependent survival values from time $t$ to $T$, also accounting for mortality during the infective stage. The parameter $D_{j, t^{\prime \prime}}^{I}$ in Eq. (5b) was the duration of the infective stage, and $M^{I}$ in Eq. (5b) was the daily mortality of the infective stage. The notation $t^{\prime \prime \prime}$ referred to the time interval of the infective stage.

The duration of the infective stage ( $D_{j, t}^{I}$ in Eq. 5b) was assumed to be temperature-dependent, following experimental results by Samsing et al. (2016):

$D_{j, t}^{I}=\exp \left\{2.6-0.26 \cdot \ln \left[\frac{T e m p_{j, t}}{10}\right]-1.03 \cdot\left[\ln \left(\frac{T e m p_{j, t}}{10}\right)\right]^{2}\right\}$

The duration of the infective stage was calculated based on the temperatures reported at the farm, by finding when the sum of developmental fractions $\left(1 / D_{j, t}^{I}\right)$ exceeded 1. Following Aldrin et al. (2017), we assumed that the daily mortality of the infective lar- val stage was identical to that of the pre-infective larval stage, $M^{I}=M^{L}$.

With this formulation, it was not necessary to correct for duration in the negative-binomial model of salmon lice counts on salmon post-smolts as a function of infestation pressure:

$$
N_{k, i, T^{\prime}}^{O b s} \sim \exp \left[\beta_{0}+\beta_{1} \ln \left(T I_{i, T^{\prime}}\right)+b_{i, T^{\prime}}+c_{i, T^{\prime}}\right]
$$

\subsubsection{Alternative dispersal function (H2)}

We considered an updated dispersal function based on analyses by Aldrin et al. (2019), here scaled to be 1 at distance 0 (Fig. 2):

$$
r_{i, j}=0.582 \cdot \exp \left[-0.374\left(d_{i, j}^{0.692}-1\right) / 0.692\right]
$$

\subsubsection{Alternative mortality rates (H3)}

As alternatives to the mortality rates of the baseline model, $M^{E}=M^{L}=M^{I}=0.17, M^{C}=0.001$, we considered $M^{E}=0.12 \mathrm{and} /$ or $M^{L}=M^{I}=0.3$. These alternative values were mortality estimates for, respectively, adult and larval (nauplii and copepodid) stages of salmon lice by Aldrin et al. (2017). We further considered $M^{C}=0.01$, which was the upper limit of plausible values for chalimus-stage daily mortality proposed by Stien et al. (2005).

\subsubsection{Alternative temperature-dependent egg and} larval development times ( $\mathrm{H} 4-\mathrm{H} 6)$

As a first step, we tested H4 by considering a model formulation in which the time delay from observa-

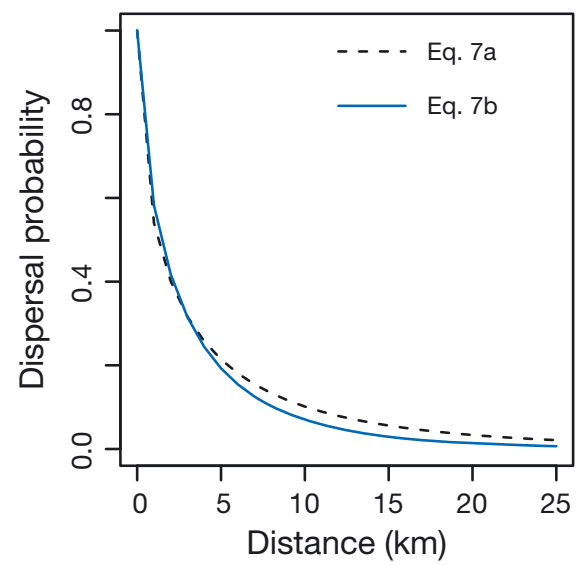

Fig. 2. Dispersal probability of salmon lice according to Aldrin et al. (2013) (black dashed line; Eq. 7a) and Aldrin et al. (2019) (blue line; Eq. 7b) 
tions of adult females to the appearance of infective larvae was not a constant function of degree-days (Eq. 6a). Instead, we used a 'development-fraction approach' (Hamre et al. 2019). Specifically, we calculated egg development time from Eq. (4a) (as already done for egg production rate) and larval development time from Eq. (11a), both estimated by Stien et al. (2005):

$$
D_{j, t}^{L}=\left[24.8 /\left(\mathrm{Temp}_{j, t}-10+24.8 \cdot 0.525\right)\right]^{2}
$$

To calculate the egg development time based on the temperatures reported at a farm, we assumed that the daily values of $1 / D_{j, t}^{E}$ described the fractional egg development and considered the eggs to be fully developed and hatch when the sum of development fractions exceeded 1. Correspondingly, the daily values of $1 / D_{j, t}^{L}$ described the fractional larval development based on the temperatures reported from the egg-hatching time onwards.

We tested $\mathrm{H} 5$ by considering an alternative function for temperature-dependent egg development, which incorporated recent experimental results by Samsing et al. (2016) and Hamre et al. (2019). In comparison, the baseline model by Kristoffersen et al. (2018) used egg and larval development times given by Stien et al. (2005). The egg development times found by Hamre et al. (2019) fitted nicely on the curve estimated by Stien et al. (2005), while Samsing et al. (2016) found lower development time than previously reported (Fig. 3a). We used the new data points (Samsing et al. 2016, Hamre et al. 2019) in addition to the data used by Stien et al. (2005) to reestimate the parameters in Eq. (4a) by nonlinear regression (Fig. 3a):

$$
D_{j, t}^{E}=\left[35.5 /\left(T e m p_{j, t}-10+35.5 \cdot 0.378\right)\right]^{2}
$$

The standard errors for the parameter estimates 35.5 and 0.378 in Eq. (4b) were, respectively, 4.1 and 0.024 . This function was used both for estimating the egg production rate (Eq. 2; Fig. 4b,c) and the time from egg production to infective stage (Eq. 5).

We tested $\mathrm{H} 6$ by considering 2 alternative functions for temperature-dependent larval development that incorporated experimental results by Samsing et al. (2016). We first re-estimated the parameters in Eq. (11a) by including the new data points from Samsing et al. (2016) in addition to the data used by Stien et al. (2005; Fig. 3b):

$$
D_{j, t}^{L}=\left[26.2 /\left(T e m p_{j, t}-10+26.2 \cdot 0.509\right)\right]^{2}
$$

The standard errors for the parameter estimates 26.2 and 0.509 were, respectively, 1.39 and 0.0147 . This function was nearly indistinguishable from the original function (Fig. 3b).

We also considered the regression equation reported by Samsing et al. (2016):

$$
D_{j, t}^{L}=1.4-1.48 \cdot \ln \left(\frac{T e m p_{j, t}}{10}\right)
$$

This function predicts longer development time than the other functions at low temperatures, particularly
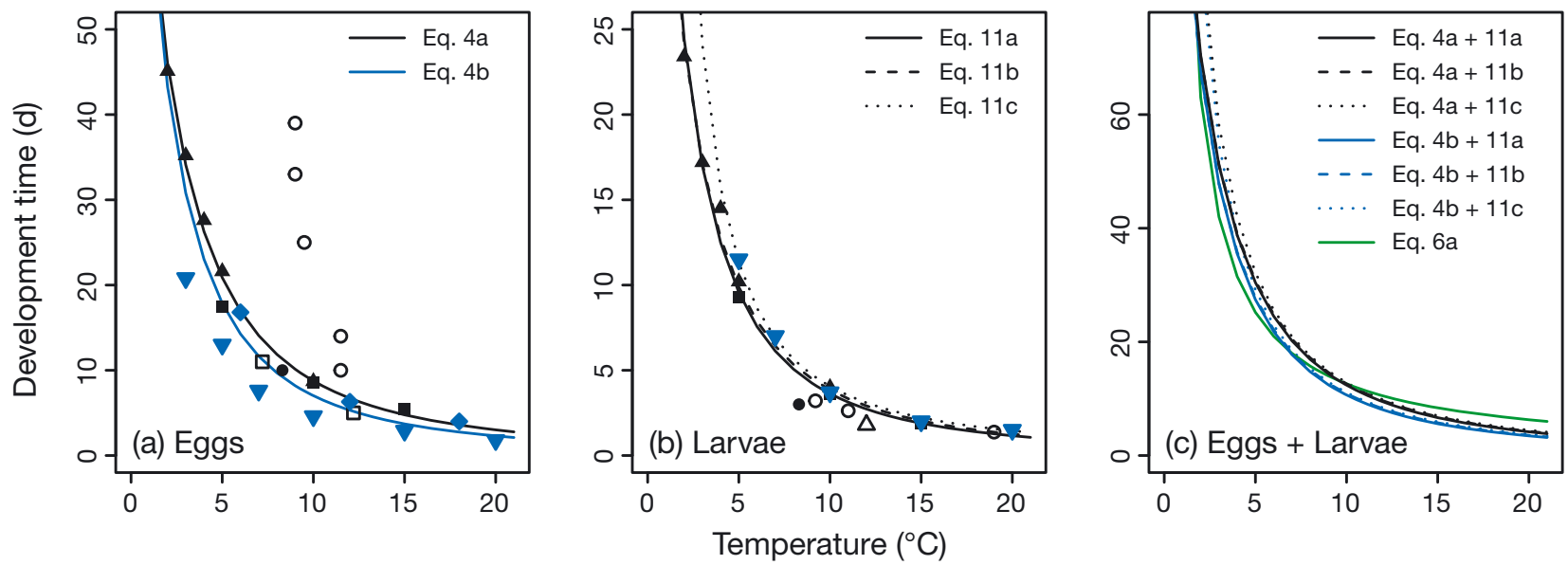

Fig. 3. (a) Egg development times of salmon lice from O Johannessen (1977), $\boldsymbol{\square}$ Johnson \& Albright (1991), $\boldsymbol{\Delta}$ Boxaspen \& Næess (2000), $\square$ Heuch et al. (2000), • Tucker et al. (2002), $\nabla$ Samsing et al. (2016, Table S1) and $\bullet$ Hamre et al. (2019, Table 5). Black filled symbols $(\mathbf{\square} \boldsymbol{\Delta})$ represent data used by Stien et al. (2005) to calculate Eq. (4a); all filled symbols $(\boldsymbol{\square} \mathbf{\Delta} \bullet \boldsymbol{\nabla} \bullet)$ represent data used to calculate the updated Eq. (4b). Lines show egg development time as a function of temperature according to Eqs. (4a) or (4b). (b) Larval development times. $\mathbf{O}, \mathbf{\square}, \boldsymbol{\Delta}, \bullet$ and $\boldsymbol{\nabla}$ refer to the same data sources as in (a), with $\Delta$ from Wootten et al. (1982). Lines show larval development time as function of temperature according to Eq. (11a) (Stien et al. 2005), Eq. (11b) (reestimated based on all the plotted data, not easily distinguishable from the line for Eq. 11a), or Eq. (11c) (Samsing et al. 2016). (c) Lines show total egg and larval egg developmental times calculated by combining the equations for eggs and larvae, or approximated by a total development time of 126 degree-days (as assumed in the baseline model; Eq. 6a) 

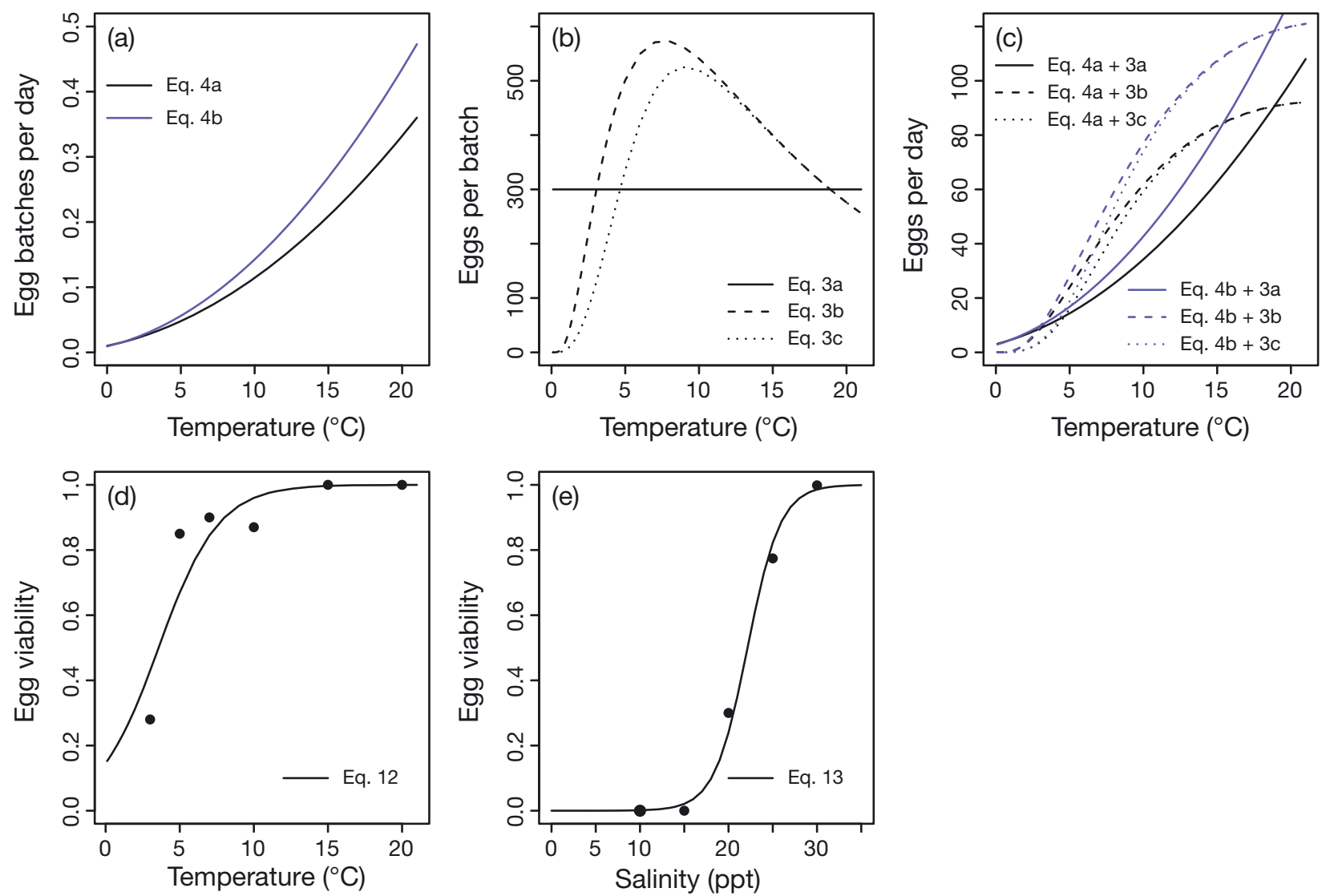

Fig. 4. Alternative egg production functions for salmon lice. (a) Number of egg batches released by each female per day. This function is the inverse of the egg development times shown in Fig. 3a (Eqs. 4a \& 4b). (b) Number of eggs per egg batch at different temperatures, assuming constant egg batch size (Eq. 3a), temperature-dependent egg batch size (Samsing et al. 2016, Eq. 3b), or temperature-dependent egg batch size and temperature-dependent egg viability (Eqs. 12 \& 3c). (c) Number of eggs released by each female per day for different functions for egg batches per day and eggs per batch. (d) Temperature effect on egg viability (logistic regression line fitted to data from Samsing et al. 2016). (e) Salinity effect on egg viability (logistic regression line fitted to data from Johnson \& Albright 1991)

below $5^{\circ} \mathrm{C}$, which was the lowest temperature assessed by Samsing et al. (2016).

\subsubsection{Temperature-dependent egg batch size (H7)}

The function for egg development time influenced the egg batch release rate (Fig. 4a), which, together with the number of eggs per batch (Fig. 4b), determined the egg production rate (Fig. 4c). As an alternative to constant egg batch size (Eq. 3a), we considered temperature-dependent egg batch size following experimental results by Samsing et al. (2016):

$B_{j, t}=2 \cdot \exp \left\{5.6-0.43 \cdot \ln \left[\frac{T e m p_{j, t}}{10}\right]-0.78 \cdot\left[\ln \left(\frac{T e m p_{j, t}}{10}\right)\right]^{2}\right\}$

This function predicts more eggs per egg batch around $5-10^{\circ} \mathrm{C}$ than at either lower or higher temperatures.

\subsubsection{Temperature-dependent egg viability (H8)}

We then took into account temperature-dependent egg viability by calculating a viability factor $\left(v^{\text {Temp }}\right.$, scaled from 0 to 1 ) that egg batch size (Eq. 3b) was multiplied with:

$B_{j, t}=2 \cdot \exp \left\{5.6-0.43 \cdot \ln \left[\frac{T e m p_{j, t}}{10}\right]-0.78 \cdot\left[\ln \left(\frac{T e m p_{j, t}}{10}\right)\right]^{2}\right\} \cdot v_{j, t}^{T e m p}$

The viability factor was a logistic function of the reported farm temperature at the time of egg formation (Fig. 4d):

$$
v_{j, t}^{T e m p}=\operatorname{logit}^{-1}\left(-1.765+0.494 T e m p_{j, t}\right)
$$

Here, $\operatorname{logit}^{-1}$ is the inverse logit function, $\operatorname{logit}^{-1}(X)=$ $\exp (X) /[1+\exp (X)]$. We calculated the temperature function based on data on the fraction of $L$. salmonis eggs that successfully hatched at temperatures from 
$3-20^{\circ} \mathrm{C}$ in experiments by Samsing et al. (2016). The logistic regression curve was fitted using the 'glm' function in $\mathrm{R}$, by assuming that each reported fraction hatched represented 100 binomial trials (this number was set high enough to avoid rounding errors and did not influence parameter estimates).

\subsubsection{Temperature-dependent infectivity (H9)}

We estimated temperature effects on infectivity from published experiments that had quantified infestation success of L. salmonis copepodids on Atlantic salmon post-smolts at 2 or more temperatures (Fig. 5a). Tucker et al. (2000) exposed the fish to newly moulted copepodids and determined infestation success $5 \mathrm{~d}$ post-exposure in 2 temperature experiments conducted at 7.2 and $11.7^{\circ} \mathrm{C}$ (experiment 1) and 6.9 and $12.8^{\circ} \mathrm{C}$ (experiment 2). Samsing et al. (2016) determined infestation success at 5, 10 and $20^{\circ} \mathrm{C}$ after, respectively, 28, 13 and $5 \mathrm{~d}$ post-exposure (when lice were estimated to be in the chalimus stages). SkernMauritzen et al. (2020) determined infestation success at 5,10 and $15^{\circ} \mathrm{C}$ as a function of copepodid age (Fig. 5b). The copepodid age spans tested by SkernMauritzen et al. (2020) corresponded approximately to previously reported temperature-dependent infective periods of copepodids (Samsing et al. 2016). As a measure of mean infestation success during the infective period, we computed average values across the duration of the experiment for each temperature (using values from Table S1 in Skern-Mauritzen et al. 2020). Dalvin et al. (2020) determined infestation success of newly moulted copepodids in 8 temperature groups from $3-10^{\circ} \mathrm{C}$ after $4-11 \mathrm{~d}$ post-exposure dependent on temperature (shown in their Fig. 1). In a second experiment, Dalvin et al. (2020) determined the combined infestation and survival success of copepodids measured from the late chalimus I stage to the appearance of adult female lice in 6 temperature groups from $6-21^{\circ} \mathrm{C}$ (shown in their Fig. 4). We used the average values for each temperature group except the $6^{\circ} \mathrm{C}$ group, as it was infected at $9^{\circ} \mathrm{C}$. Further, we considered the $9-15$ and $18-21^{\circ} \mathrm{C}$ groups as different experiments because different copepodid batches were used.

By analysing the data from all experiments using a mixed-effects generalized linear model, we found that infestation success ( $I$, scaled from $0-1)$ could be explained as a function of temperature $\left(\mathrm{Temp}^{\circ}{ }^{\circ} \mathrm{C}\right)$ with the following equation (Fig. 5a):

$$
I=\operatorname{logit}^{-1}\left(-3.89+4.33 \frac{\text { Temp }}{10}-1.18 \frac{T_{e m p}^{2}}{10}\right)
$$

The standard errors for the coefficients $-3.89,4.33$ and -1.18 were $0.33,0.13$ and 0.06 , respectively. The effect of experimental settings on expected infestation success was accounted for by a random effect
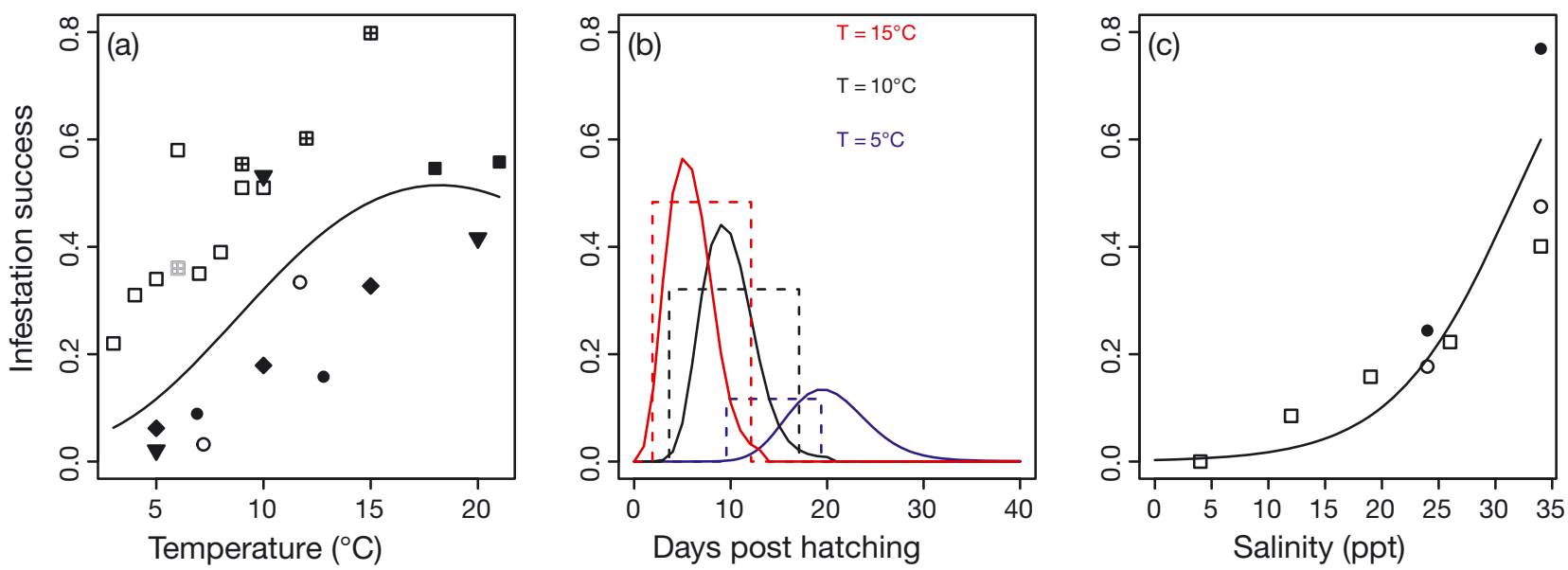

Fig. 5. Temperature- and salinity-dependent infestation success of salmon lice. (a) Points show infestation success as function of temperature in different experiments: O Expt 1 by Tucker et al. (2000), • Expt 2 by Tucker et al. (2000), $\boldsymbol{\nabla}$ Samsing et al. (2016), Skern-Mauritzen et al. (2020), $\square$ Expt 1 by Dalvin et al. (2020), $⿴ 囗 十$ batch 1 in Expt 2 by Dalvin et al. (2020, with the 6 degrees group shown in grey infected at 9 degrees and not used to fit the regression line), $\mathbf{\square}$ batch 2 in Expt 2 by Dalvin et al. (2020). Line: regression line fitted by a mixed-effects model with a random effect of experiment (Eq. 13a). (b) Infection success as function of days post-hatching at 3 different temperatures. Unbroken lines: time-varying infectivity as estimated by SkernMauritzen et al. (2020, Eq. 13b). Broken lines: constant infectivity, with temperature effect on infection success according to Eq. (14a), larval development time according to Eq. (11b) and duration of infective stage according to Eq. (10). (c) Points show infestation success as function of salinity in different experiments: 0 Expt 3 by Tucker et al. (2000), • Expt 4 by Tucker et al. (2000), $\square$ Bricknell et al. (2006). Line: regression line fitted by a mixed-effects model with a random effect of experiment, which accounted for differences in experimental setup between studies (Eq. 13c) 
of experiment in the model (with an estimated standard deviation of 0.86). The number of successful and unsuccessful copepodids in each experiment were assumed to be binomially distributed and the model was fitted using the 'glmer' function in the 'Ime4' package in R. To apply the correction in our model, we scaled infestation pressure using Eq. (13a) and average NorKyst800 sea temperature at the experimental cage location during the experimental period.

As an alternative, we used the function for temperature- and time-dependent infectivity reported by Skern-Mauritzen et al. (2020, see Fig. 5b):

$$
\begin{aligned}
I_{j, t}= & \operatorname{logit}^{-1}\left(-34.66+2.306 \text { Temp }_{j, t}-0.02585 \text { Temp }_{j, t}^{2}+\right. \\
& 0.7156 A_{j, t}-0.005354 A_{j, t}^{2}+0.00001191 A_{j, t}^{3}- \\
& 0.03577 \text { Temp }_{j, t} A_{j, t}+0.0002525 \text { Temp }_{j, t} A_{j, t}^{2}- \\
& \left.0.0000005541 \operatorname{Temp}_{j, t} A_{j, t}^{3}\right)
\end{aligned}
$$

Here, infectivity of lice larvae from farm $j$ at time $t$ is a function of farm temperatures and age measured in degree-days after hatching ( $A_{j, t} ;$ degree-days). As this polynomial function predicted unrealistic increases in infectivity at very high ages, we set $I_{j, t}=0$ for $A_{j, t}>200$ degree-days. For computational reasons, we also assumed that larvae remained infective for a maximum of $40 \mathrm{~d}$ after hatching. To avoid extrapolation, we used predicted values for $5^{\circ} \mathrm{C}$ for all temperatures $\leq 5^{\circ} \mathrm{C}$ and predicted values for $15^{\circ} \mathrm{C}$ for all temperatures $\geq 15^{\circ} \mathrm{C}$. Note that as Eq. (13b) gave infectivity as a continuous function of time since hatching, larval development time did not enter into this model formulation. We then used the following equation to calculate the fraction of eggs produced from farm $j$ at time $t$ that were infectious larvae at time $T\left(s_{j, t, T}^{\prime}\right.$ in Eq. 1b):

$$
s^{\prime}{ }_{j, t, T}=\left\{\begin{array}{l}
\left(1-M^{E}\right)^{D_{j, t^{\prime}}^{E}} \cdot\left(1-M^{L}\right)^{T-D_{j, t^{\prime}}^{E}-t} \cdot I_{j, T}, \\
\quad \text { if } D_{j, t^{\prime}}^{E} \leq(T-t) \leq\left(D_{j, t^{\prime}}^{E}+40\right) \\
0, \quad \\
\quad \text { if }(T-t)<D_{j, t^{\prime}}^{E} \mid(T-t)>\left(D_{j, t^{\prime}}^{E}+40\right)
\end{array}\right.
$$

The terminology follows that of Eq. (5b). Note that for computational reasons this correction was based on temperatures at the farm from which the larvae originated.

\subsubsection{Salinity-dependent egg viability (H10)}

We considered a model formulation in which egg production depended on a salinity-dependent egg viability factor, $v^{S a l}$ :

$$
\begin{aligned}
B_{j, t}= & 2 \cdot \exp \left\{5.6-0.43 \cdot \ln \left[\frac{\text { Temp }_{j, t}}{10}\right]-0.78 \cdot\left[\ln \left(\frac{\text { Temp }_{j, t}}{10}\right)\right]^{2}\right\} \\
& \cdot V_{j, t}^{T e m p} \cdot V_{j, t}^{S a l}
\end{aligned}
$$

This factor was a logistic function of farm-location salinity (Sal; ppt) from NorKyst800 at the time of egg formation (Fig. 4e):

$$
V_{j, t}^{S a l}=\operatorname{logit}^{-1}\left(-11.92+0.538 S a l_{j, t}\right)
$$

We calculated the salinity function based on experimental results on the percentage of $L$. salmonis oncorhynchi eggs that developed into active nauplii for salinities ranging from $10-30 \mathrm{ppt}$ at $10^{\circ} \mathrm{C}$ (using data from Table 3 in Johnson \& Albright 1991). We considered viability at $30 \mathrm{ppt}(65.9 \%)$ to represent a baseline viability $\left(v^{S a l}=1\right)$ and rescaled the data by dividing on this value before fitting a logistic regression curve to the rescaled data (i.e. Eq. 14, with assumptions as for Eq. 12).

\subsubsection{Salinity-dependent infectivity (H11)}

We estimated salinity-dependent infectivity from published experiments that had quantified infestation success of L. salmonis copepodids on Atlantic salmon post-smolts at 2 or more salinity levels (Fig. 5c). Tucker et al. (2000) determined infestation success in 2 salinity experiments, both conducted at 24 and 34 ppt. Bricknell et al. (2006) determined infestation levels following short-term exposure to reduced salinity, investigating 5 salinities from 4-34 ppt. We scaled the reported number of attached lice after $6 \mathrm{~d}$ to proportions by assuming $40 \%$ infestation success at $34 \mathrm{ppt}$, which is the predicted infestation success at the experimental temperature of $12^{\circ} \mathrm{C}$ according to Eq. (13a). By analysing the data using a mixedeffects generalized linear model (similarly to temperature), we found that infestation success $\left(I_{i}\right.$ scaled from 0-1) could be explained as a function of salinity with the following equation (Fig. 5c):

$$
I=\operatorname{logit}^{-1}(-5.88+0.185 \text { Sal })
$$

The standard errors for the coefficients -5.88 and 0.185 were 0.25 and 0.003 , respectively, and the random effect of experiment had a standard deviation of 0.40. There were not enough data to reliably estimate possible non-linear effects of salinity. When testing for salinity effects on infestation success, we also applied the correction for temperature (Eq. 13a) by assuming that the salinity and temperature effects were additive on the linear scale of the predictors and scaling the intercept so that infestation success at a salinity of 34 ppt was as given by Eq. (13a): 
$I=\operatorname{logit}^{-1}\left[-3.89+4.33 \frac{T e m p}{10}-1.18 \frac{T e m p^{2}}{10}+0.185(\right.$ Sal -34$\left.)\right]$

\subsubsection{Statistical estimation of additional temperature and salinity effects (H12)}

The available experimental data were not sufficient to pre-define functions for temperature and salinity effects on mortality rates. Environmental effects on mortality during the planktonic stages are difficult to assess experimentally because of the likely key role of predation as a mortality cause (Brooker et al. 2018) and because the larvae may actively avoid water layers with unfavourable physical conditions (Crosbie et al. 2019). To investigate possible additional environmental effects, we estimated these functions from the data by entering temperature and salinity as covariates in the negative-binomial model of salmon lice counts on salmon post-smolts as a function of infestation pressure:

$N_{k, i, T^{\prime}}^{O b s} \sim \exp \left[\beta_{0}+\beta_{1} \ln \left(T I_{i, T^{\prime}}\right)+F\left(T e m p_{i, T^{\prime}}, S a l_{i, T^{\prime}}\right)+b_{i, T^{\prime}}+C_{i, T^{\prime}}\right]$

The terminology follows that for Eqs. (9a) \& (9b), with the addition of a function of mean NorKyst800 temperature and salinity at the cage location during the experiment, $F\left(\operatorname{Temp}_{i, T^{\prime}}, S a l_{i, T^{\prime}}\right)$. Preliminary analyses using generalized additive models (Wood 2017) suggested that the temperature effect could be approximated by a quadratic function and the salinity effect by a linear function:

$$
\begin{aligned}
F\left(\operatorname{Temp}_{i, T^{\prime},} \operatorname{Sal}_{i, T^{\prime}}\right)= & \beta_{2}\left(\operatorname{Temp}_{i, T^{\prime}}-12\right)+ \\
& \beta_{3}\left(\operatorname{Temp}_{i, T^{\prime}}-12\right)^{2}+ \\
& \beta_{4}\left(\operatorname{Sal}_{i, T^{\prime}}-27\right)
\end{aligned}
$$

Temperature and salinity values were centred at $12^{\circ} \mathrm{C}$ and $27 \mathrm{ppt}$ for more stable model estimation. We also considered a formulation with non-additive effects (interaction terms) of temperature and salinity:

$$
\begin{aligned}
F\left(\operatorname{Temp}_{i, T^{\prime},} \mathrm{Sal}_{i, T^{\prime}}\right)= & \beta_{2}\left(\operatorname{Temp}_{i, T^{\prime}}-12\right)+ \\
& \beta_{3}\left(\operatorname{Temp}_{i, T^{\prime}}-12\right)^{2}+ \\
& \beta_{4}\left(\operatorname{Sal}_{i, T^{\prime}}-27\right)+ \\
& \beta_{5}\left(\operatorname{Temp}_{i, T^{\prime}}-12\right)\left(\operatorname{Sal}_{i, T^{\prime}}-27\right)+ \\
& \beta_{6}\left(\operatorname{Temp}_{i, T^{\prime}}-12\right)^{2}\left(\operatorname{Sal}_{i, T^{\prime}}-27\right)
\end{aligned}
$$

\subsection{Model development}

The model development was done stepwise. We first assessed whether using the alternative calculation of infestation pressure (H1) improved the explanatory power; second, the alternative distance function (H2); and third, the alternative mortality rates (H3). We then found the combination of development time functions $(\mathrm{H} 4-\mathrm{H} 6)$ that gave the best explanatory power. Subsequently, we assessed possible temperature dependence in egg batch size (H7), egg viability (H8) and larval infectivity (H9). Because of correlation between temperatures at different developmental stages, we reconsidered H7H8 when testing H9. We then tested for possible salinity dependence in egg viability (H10) and/or infectivity (H11). We finally added temperature and salinity to the selected model. The explanatory power was assessed using sentinel cage data from 2012-2017. The explanatory power was measured based on the random-effect estimates in the negative binomial model, which showed the unexplained variance between area-year-periods $\left(\sigma_{1}{ }^{2}\right)$ and between cages within area-year-periods $\left(\sigma_{2}{ }^{2}\right)$. We aimed to reduce both variance components and considered the infestation pressure to be more accurate if the sum of the random-effect variance $\left(\sigma_{1}{ }^{2}\right.$ $+\sigma_{2}{ }^{2}$ ) was reduced. Statistically estimated temperature and salinity terms (H12) were included in the final model if the random-effect variance was reduced and the terms were statistically significant at $\mathrm{p}<0.05$.

The capability of the model to predict lice abundance in sentinel cages was assessed by linear regression (following Kristoffersen et al. 2018):

$$
\ln \left(\bar{N}_{i, T}^{O b s}+0.033\right)=\beta_{0}+\beta_{1} \ln \left(\bar{N}_{i, T}^{\text {Pred }}+0.033\right)+\varepsilon_{i, T}
$$

Here, $\bar{N}_{i, T}^{O b s}$ is the mean number of lice per fish in sentinel cage $i$ at time $T, \bar{N}_{i, T}^{\text {Pred }}$ is the expected mean abundance, $\beta_{0}$ is the intercept, $\beta_{1}$ is the slope, and $\varepsilon_{i, T}$ is a normal-distributed error term. We added 0.033, being the lowest non-zero observation, to avoid taking the logarithm of zero.

\subsection{Assessment of predictive power}

We used sentinel cage data from 2018-2020 to assess the out-of-sample predictive power of the model. This data set included 298 sentinel cages that were not used in model development. Predictions of expected mean abundance per cage were calculated from alternative models (parameterized for 2012-2017 data) and compared with the cage data observations (20182020) by using linear regression (Eq. 16). The input data for the predictions were, as for the model fitting, the reported lice counts and temperatures at farms, NorKyst800 salinities at farms and NorKyst800 tem- 
peratures and salinities at sentinel cage locations. We approximated $95 \%$ prediction intervals for expected mean abundance by the interval $\left(\mathrm{e}^{\ln \left(\bar{N}_{i, T}^{\text {Pred }}\right)-2 \sqrt{\sigma_{1}{ }^{2}+\sigma_{2}{ }^{2}}}\right.$, $\mathrm{e}^{\left.\ln \left(\bar{N}_{i, T}^{\text {Pred }}\right)+2 \sqrt{\sigma_{1}{ }^{2}+\sigma_{2}{ }^{2}}\right)}$. Note that these intervals show the uncertainty caused by random variability between time periods, areas and cages, but not the uncertainty in model parameters. We calculated predictions from the baseline model, the final model, as well as from selected models from intermediate steps of the model selection. To measure predictive power, we calculated root-mean-squared prediction error (RMSE) and mean absolute prediction error (MAPE), both on scale $\ln \left(\bar{N}_{i, T}+0.033\right)$.

The statistical computing platform $\mathrm{R}$ version 3.61 (R Core Team 2019) was used for all analyses. The mixed-effects models were fitted using the 'glmer.nb' function in the $\mathrm{R}$ package 'lme4' version 1.1-21 (Bates et al. 2015).

\section{RESULTS}

\subsection{Which model formulations (H1-H11) provided most accurate calculation of infestation pressure for 2012-2017?}

The calculation of infestation pressure became more accurate by using cumulative infestation pressure (H1, Eq. 8b) and the new distance function (H2, Eq. $7 \mathrm{~b}$ ). With these changes in the calculation of infestation pressure, the unexplained variance between cages $\left(\sigma_{1}{ }^{2}+\sigma_{2}{ }^{2}\right)$ was reduced from 2.18 to 1.92 and $\mathrm{R}^{2}$ increased from 0.378 to 0.417 (Table 1).

We found no improvement in model accuracy by decreasing egg mortality to $0.12 \mathrm{~d}^{-1}$, increasing larval mortality to $0.3 \mathrm{~d}^{-1}$ and/or increasing chalimus mortality to $0.01 \mathrm{~d}^{-1}$ (H3; Table 1 ).

The calculations became slightly more accurate by using the 'developmental fraction' approach (H4,

Table 1. Salmon lice model development. Lice counts for 2012-2017 were analysed in a negative binomial model as a function of ln-scale infestation pressure (IP) ( $\mathrm{n}=756$ sentinel cages with a total of $18573 \mathrm{fish}$ ). The model included random effects of area-year-period and cage, with standard deviations $\sigma_{1}$ and $\sigma_{2}$, respectively. At each step of the model development, we considered the calculated IP to be more accurate if the unexplained variance $\left(\sigma_{1}{ }^{2}+\sigma_{2}{ }^{2}\right)$ was reduced. The dispersion parameter was estimated to be $\theta=15.3$ for all models. An asterisk $\left({ }^{*}\right)$ implies that a hypothesis $(\mathrm{H})$ was supported and the modification was applied to all subsequent models shown. An asterisk in parentheses for H10 means that the hypothesis was not supported when reassessed after applying the correction tested under $\mathrm{H} 11$ and hence not applied. The linear model analysed cage-level lice count data (observed versus predicted) for the same years, with the regression equation being unbiased if the intercept was near 0 and the slope near $1 . \mathrm{R}^{2}$ was the amount of variance explained by the linear model. None: variation in lice counts without IP as a predictor in the negative binomial model. The baseline model used IP: Eq. (8a); distance function: Eq. (7a); total development time: Eq. (6); egg. dev.: Eq. (4a); egg mortality: $0.17 \mathrm{~d}^{-1}$; larval mortality: $0.17 \mathrm{~d}^{-1}$; and chalimus mortality: $0.001 \mathrm{~d}^{-1}$. Total development time in the development fraction approach (Eq. 11a) initially used egg development time: Eq. (4a); larval development time: Eq. (11a). The last 2 rows show results when salinity (Sal) and temperature (Temp) were covariates to total infestation pressure (TI) in the negative binomial model (Eq. 9c). Temp was included as a quadratic term, either additively (Eq. 15a) or non-additively (Eq. 15b; shown by the symbol $x$ ) to salinity. $y=\ln ($ mean observed salmon lice per fish in a cage +0.033 ); $\hat{y}=\ln ($ predicted mean salmon lice per fish in a cage +0.033$)$

\begin{tabular}{|c|c|c|c|c|c|}
\hline \multirow[t]{2}{*}{ IP calculation } & \multicolumn{3}{|c|}{ Negative binom. model } & \multicolumn{2}{|c|}{ Linear model of cage-level data -} \\
\hline & $\sigma_{1}$ & $\sigma_{2}$ & $\sigma_{1}^{2}+\sigma_{2}^{2}$ & Regression equation & $\mathrm{R}^{2}$ \\
\hline None (constant IP) & 1.40 & 1.13 & 3.22 & $y=-0.19 \pm 0.06$ & 0 \\
\hline Baseline model & 1.21 & 0.85 & 2.18 & $y=-0.08 \pm 0.05+0.82 \pm 0.04 \hat{y}$ & 0.378 \\
\hline${ }^{*}$ H1. Cumulative IP: Eq. (8b) & 1.20 & 0.83 & 2.14 & $y=-0.09 \pm 0.05+0.85 \pm 0.04 \hat{y}$ & 0.412 \\
\hline${ }^{*} \mathrm{H} 2$. New distance func.: Eq. (7b) & 1.11 & 0.84 & 1.92 & $y=-0.02 \pm 0.05+1.01 \pm 0.04 \hat{y}$ & 0.417 \\
\hline H3. Egg mortality $0.12 \mathrm{~d}^{-1}$ & 1.12 & 0.84 & 1.95 & $\mathrm{y}=-0.01 \pm 0.05+1.03 \pm 0.05 \hat{\mathrm{y}}$ & 0.412 \\
\hline H3. Larval mortality $0.3 \mathrm{~d}^{-1}$ & 1.12 & 0.84 & 1.96 & $y=-0.03 \pm 0.05+0.99 \pm 0.04 \hat{y}$ & 0.412 \\
\hline H3. Chalimus mortality $0.01 \mathrm{~d}^{-1}$ & 1.11 & 0.84 & 1.93 & $y=-0.02 \pm 0.05+1.01 \pm 0.04 \hat{y}$ & 0.416 \\
\hline${ }^{*}$ H4. Dev. frac. approach: Eq. (11a) & 1.08 & 0.83 & 1.87 & $y=-0.03 \pm 0.05+0.98 \pm 0.04 \hat{y}$ & 0.426 \\
\hline H5. New egg dev. time: Eq. (4b) & 1.11 & 0.83 & 1.92 & $y=-0.03 \pm 0.05+0.99 \pm 0.04 \hat{y}$ & 0.421 \\
\hline${ }^{*}$ H6. Larv. dev. time: Eq. (11b) & 1.08 & 0.83 & 1.87 & $y=-0.03 \pm 0.05+0.98 \pm 0.04 \hat{y}$ & 0.425 \\
\hline H6. Larv. dev. time: Eq. (11c) & 1.08 & 0.84 & 1.87 & $\mathrm{y}=-0.03 \pm 0.05+0.98 \pm 0.04 \hat{\mathrm{Y}}$ & 0.424 \\
\hline${ }^{*}$ H7. Temp. dep. egg batch: Eq. (3b) & 1.08 & 0.83 & 1.86 & $y=-0.02 \pm 0.04+1.00 \pm 0.04 \hat{y}$ & 0.430 \\
\hline${ }^{*}$ H8. Temp. dep. egg viabil.: Eq. (3c) & 1.07 & 0.83 & 1.85 & $y=-0.03 \pm 0.04+1.00 \pm 0.04 \hat{y}$ & 0.432 \\
\hline${ }^{*}$ H9. Temp. dep. infectivity: Eq. (13a) & 1.06 & 0.83 & 1.82 & $\mathrm{y}=-0.04 \pm 0.04+0.96 \pm 0.04 \hat{\mathrm{y}}$ & 0.435 \\
\hline H9. Temp. dep. infectivity: Eq. (13b) & 1.06 & 0.84 & 1.83 & $y=-0.04 \pm 0.04+0.95 \pm 0.04 \hat{y}$ & 0.434 \\
\hline$\left({ }^{*}\right)$ H10. Sal. dep. egg viabil.: Eq. (3d) & 1.06 & 0.82 & 1.79 & $y=-0.04 \pm 0.04+0.97 \pm 0.04 \hat{y}$ & 0.442 \\
\hline${ }^{*}$ H11. Sal. dep. infectivity.: Eq. (13d) & 1.04 & 0.77 & 1.66 & $y=-0.00 \pm 0.04+1.03 \pm 0.04 \hat{y}$ & 0.453 \\
\hline H12. TI + Temp + Temp $^{2}$ & 0.97 & 0.76 & 1.52 & $\mathrm{y}=-0.02 \pm 0.04+0.99 \pm 0.04 \hat{\mathrm{y}}$ & 0.477 \\
\hline H12. TI + Sal $\times\left(\right.$ Temp $\left.+\mathrm{Temp}^{2}\right)$ & 0.98 & 0.75 & 1.52 & $y=-0.03 \pm 0.04+0.98 \pm 0.04 \hat{y}$ & 0.476 \\
\hline
\end{tabular}


Eq. $11 \mathrm{a}$; leading to unexplained variance $\sigma_{1}{ }^{2}+{\sigma_{2}}^{2}=$ 1.87 and $\mathrm{R}^{2}=0.426$ ) but slightly less accurate by including the newest estimates of egg development time (H5, Eq. 4b). The old egg development time function (Eq. 4a) was used in the subsequent models shown in Table 1. We found no practical change in model accuracy by changing the larval development time function (H6, Eqs. 11a, 11b \& 11c; Table 1). We used Eq. (11b) in subsequent models shown in Table 1, as this function integrated results from the highest number of studies.

We found that model accuracy was only marginally improved by including temperature-dependent egg batch size (H7, Eq. 3b), with unexplained variance $\sigma_{1}{ }^{2}+\sigma_{2}{ }^{2}=1.86$ and $R^{2}=0.430$ (Table 1). Model accuracy was further slightly improved by accounting for temperature-dependent egg viability (H8, Eq. 3c) and temperature-dependent infectivity (H9, Eq. 13a), resulting in unexplained variance $\sigma_{1}{ }^{2}+\sigma_{2}{ }^{2}=1.82$ and $\mathrm{R}^{2}=0.435$ (Table 1). Accounting for temperature- and time-dependent infectivity (Eq. 13b) provided similar explanatory power as Eq. (13a) (Table 1). The apparent small advantage of Eq. (13a) over (13b) in Table 1 is possibly caused by Eq. (13a) using temperatures at experimental cage locations, while Eq. (13b) used farm temperatures. If both used farm temperatures, Eq. (13a) performed slightly worse $\left(\sigma_{1}{ }^{2}+\sigma_{2}{ }^{2}=1.84\right.$ and $\mathrm{R}^{2}=$ $0.432)$ than Eq. (13b).

The largest improvement in explanatory power came when accounting for salinity. The correction for salinity-dependent egg viability (H10, Eq. 3d) was initially supported, but not when salinity-dependent infectivity (H11, Eq. 13d) was included (Table 1). The best model hence corrected for salinity dependence in infectivity but not egg viability, and resulted in unexplained variance $\sigma_{1}{ }^{2}+{\sigma_{2}}^{2}=1.66$ and $\mathrm{R}^{2}=0.453$ (compared to $\sigma_{1}{ }^{2}+\sigma_{2}{ }^{2}=1.68$ and $\mathrm{R}^{2}=0.447$ with both salinity corrections).

\subsection{Statistical estimation of additional salinity and temperature effects (H12)}

The linear effects of salinity and temperature were not statistically sig- nificant, but the quadratic temperature term was highly significant (Table 2, Fig. 6). This finding implied an association between sea temperature and lice abundance beyond the temperature effects that were assumed in the calculation of infestation pressure. Specifically, the results suggested lower lice abundance than expected from the infestation pressure at both low and high temperatures, with an estimated $75 \%$ reduction for $8^{\circ} \mathrm{C}$ compared to $12^{\circ} \mathrm{C}$, and $58 \%$ reduction for $16^{\circ} \mathrm{C}$ compared to $12^{\circ} \mathrm{C}$. Adding a quadratic effect of temperature during sentinel cage experiments resulted in a reduction in unexplained variance to $\sigma_{1}{ }^{2}+\sigma_{2}{ }^{2}=1.52$ and an increase in $R^{2}$ to 0.477 (Table 1).

There were significant interaction effects between salinity and temperature (Fig. 7), although the unexplained variance was similar for the interaction model and the additive model (Table 1). This analysis suggested that lice abundance was most strongly reduced when both salinity and temperature were sub-

Table 2. Parameter estimates for additive effects of temperature and salinity on salmon lice (Eqs. 9c \& 15a). Random-effect standard deviations were $\sigma_{1}=$ 0.98 and $\sigma_{2}=0.76$, and the dispersion parameter was $\theta=15.3$ in both the full model and the reduced model with the non-significant salinity term removed. Sample size was $n=756$ sentinel cages with a total of 18573 fish. ${ }^{*} p<0.05$; ${ }^{* *} \mathrm{p}<0.01 ;{ }^{* * *} \mathrm{p}<0.001$

\begin{tabular}{|c|c|c|c|}
\hline \multirow{2}{*}{$\begin{array}{l}\text { Coeffi- } \\
\text { cient }\end{array}$} & \multirow[t]{2}{*}{ Interpretation } & \multicolumn{2}{|c|}{ Coefficient (mean \pm SE) } \\
\hline & & Full model & Reduced model \\
\hline$\beta_{0}$ & Intercept & $-6.17 \pm 0.37^{* * *}$ & $-6.01 \pm 0.30^{* * *}$ \\
\hline$\beta_{1}$ & Infestation pressure effect & $0.452 \pm 0.023^{* * *}$ & $0.441 \pm 0.017^{* * *}$ \\
\hline$\beta_{2}$ & Linear temperature effect & $0.053 \pm 0.055$ & $0.064 \pm 0.053$ \\
\hline$\beta_{3}$ & Quadratic temperature effect & $-0.072 \pm 0.020^{* * *}$ & $-0.070 \pm 0.019^{* * *}$ \\
\hline$\beta_{4}$ & Salinity effect & $-0.0064 \pm 0.0088$ & \\
\hline
\end{tabular}
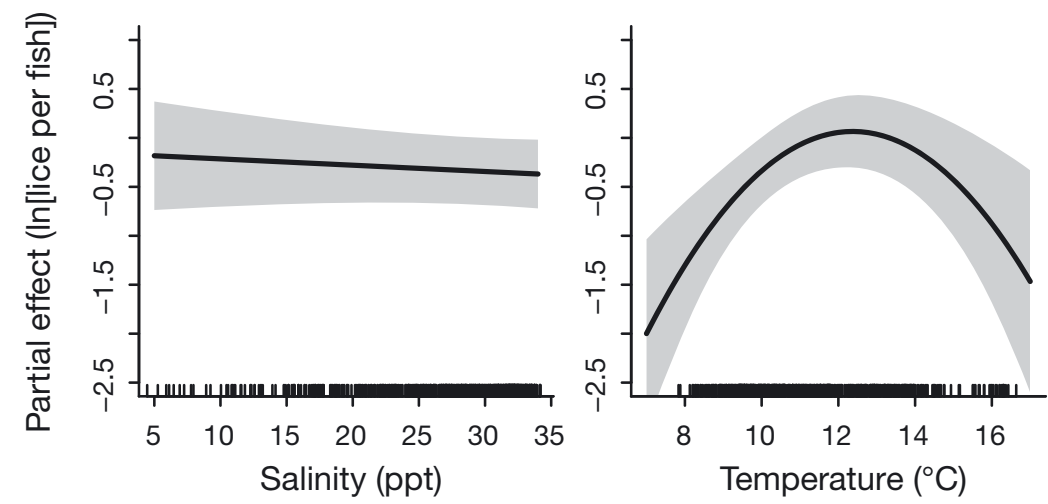

Fig. 6. Estimated additive effects of salinity and temperature on $\ln$ (lice per fish). The figure shows partial effects with $95 \%$ pointwise confidence bands. The model also includes infestation pressure as a covariate, which assumes temperature-dependent production of lice larvae and temperature- and salinity-dependent infectivity. The tick marks on the $x$-axes show the locations of the data 

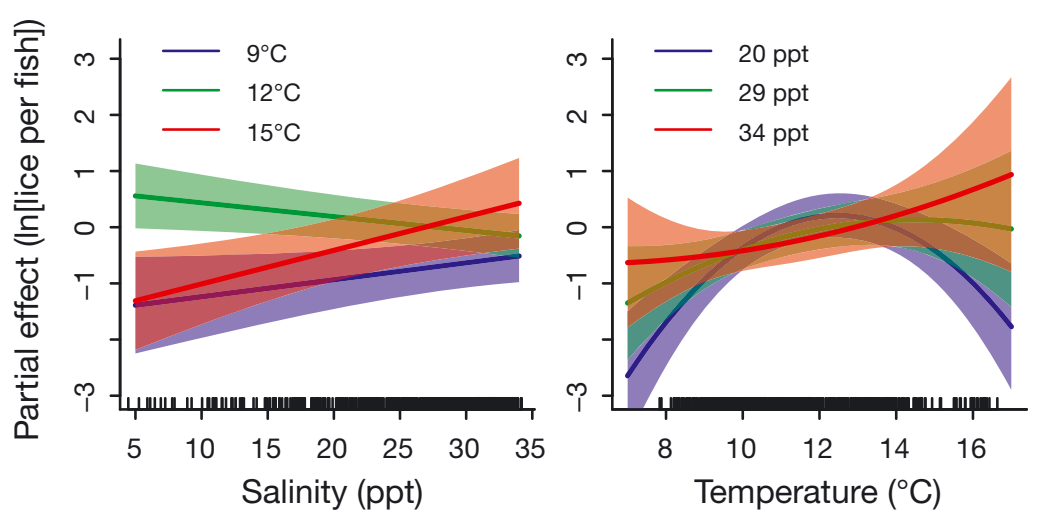

Fig. 7. Estimated non-additive effects of salinity and temperature on $\ln$ (lice per fish). The figure shows partial effects with $95 \%$ pointwise confidence bands. Estimated salinity effects at 3 representative temperatures are shown in the left-side panel. Estimated temperature effects at 3 representative salinities are shown in the right-side panel. The model also includes infestation pressure as a covariate, which assumes temperature-dependent production of lice larvae and temperature- and salinity-dependent infectivity. The tick marks on the $x$ axes show the locations of the data. The interaction effect between salinity and the quadratic temperature term is highly significant $(p<0.001)$ while that between salinity and the linear temperature term is not statistically significant

$$
(\mathrm{p}=0.2)
$$

optimal. That is, low temperatures were estimated to have the strongest negative effect on lice abundance when salinity was also low, and high temperatures appeared only to have adverse effects when salinity was low (Fig. 7, right panel).

Note that salinity and temperature during sentinel cage experiments not only measured physical conditions of lice larvae when they potentially infected salmon hosts but also correlated with conditions earlier in life. The corrections for temperature-dependent egg viability (i.e. the difference in infestation pres-

Table 3. Out-of-sample predictive power for salmon lice infestations in 20182020 ( $\mathrm{n}=298$ sentinel cages). Coverage is the proportion of observations within the $95 \%$ prediction interval. Variance explained $\left(\mathrm{R}^{2}\right)$, root-mean-squared prediction error (RMSE) and mean absolute prediction error (MAPE) were calculated based on mean observed and predicted lice per cage at the scale $\ln$ (lice per cage +0.033 ). TI: total infestation pressure

\begin{tabular}{|c|c|c|c|c|}
\hline $\begin{array}{l}\text { Infestation pressure (IP) } \\
\text { calculation }\end{array}$ & Coverage & $\mathrm{R}^{2}$ & RMSE & MAPE \\
\hline Baseline model & 0.96 & 0.19 & 1.28 & 1.00 \\
\hline H1. Cumulative IP: Eq. (8b) & 0.97 & 0.19 & 1.24 & 0.95 \\
\hline H2. New distance func.: Eq. (7b) & 0.97 & 0.19 & 1.23 & 0.95 \\
\hline H4. Dev. frac. approach: Eq. (11a) & 0.96 & 0.18 & 1.23 & 0.95 \\
\hline H6. Larv. dev. time: Eq. (11b) & 0.96 & 0.18 & 1.23 & 0.95 \\
\hline H7. Temp. dep. egg batch.: Eq. (3b) & 0.96 & 0.19 & 1.22 & 0.94 \\
\hline H8. Temp. dep. egg viabil.: Eq. (3c) & 0.96 & 0.18 & 1.23 & 0.95 \\
\hline H9. Temp. dep. infectivity: Eq. (13a) & 0.96 & 0.19 & 1.23 & 0.95 \\
\hline H11. Sal. dep. infectivity: Eq. (13d) & 0.93 & 0.08 & 1.40 & 1.13 \\
\hline H12. TI + Temp + Temp $^{2}$ & 0.91 & 0.09 & 1.43 & 1.16 \\
\hline
\end{tabular}

sure calculated using Eqs. 3b \& 3c) were strongly correlated with the temperature during sentinel cage experiments (Spearman's rank correlation, $\rho=0.82$ ). Similarly, the corrections for salinity-dependent egg viability were strongly correlated with the salinity during sentinel cage experiments $(\rho=$ 0.65). Salinity at cage locations was, on the other hand, not strongly correlated with temperature (Pearson's coefficient of correlation, $r=-0.32$ ), allowing us to assess the individual contributions of both these factors.

\subsection{Predictions for $2018-2020$}

The 95\% prediction intervals for expected mean lice abundance per cage contained the observed mean value for $91-97 \%$ of the 298 sentinel cages in 2018-2020 (depending on model formulation; Table 3). For models without the statistically estimated temperature effect (H12), the prediction intervals contained the observed value in 93-97\% of the cases. Hence, these intervals were reasonable approximations of the uncertainty of the predictions.

Predictions for 2018-2020 became more accurate by using cumulative infestation pressure (H1, Eq. 8b) and the new distance function (H2, Eq. 7b). With these changes in the calculation of infestation pressure, RMSE was reduced from 1.28 to 1.23 and MAPE from 1.00 to 0.95 (Table 3 ). The predictive power remained practically unchanged by using the 'developmental fraction' approach (H4, Eq. 11a), changing the larval development time function (H6, Eq. 11b) and including temperature-dependent egg batch size (H7, Eq. 3b), temperature-dependent egg viability (H8, Eq. 3c) and temperature-dependent infestation rate (H9, Eq. 13a). Including salinity-dependent infestation rate (H11, Eq. 13d) led to worse predictions for 2018-2020 (Table 3, Fig. 8). Predictive power also became worse by adding the statistically estimated temperature function (H12, using the reduced model in Table 2), with RMSE increasing to 1.43 and MAPE increasing to 1.16 (Table 3). 
a. Baseline model

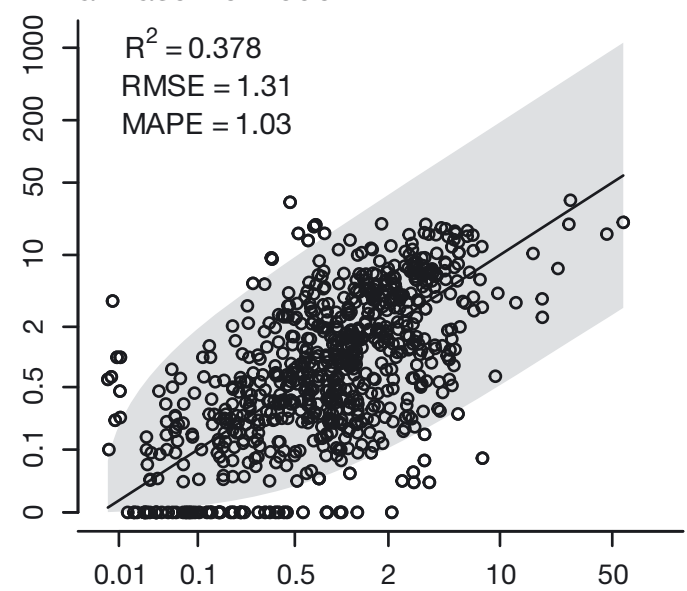

c. Best model without salinity $(\mathrm{H} 1-\mathrm{H} 9)$

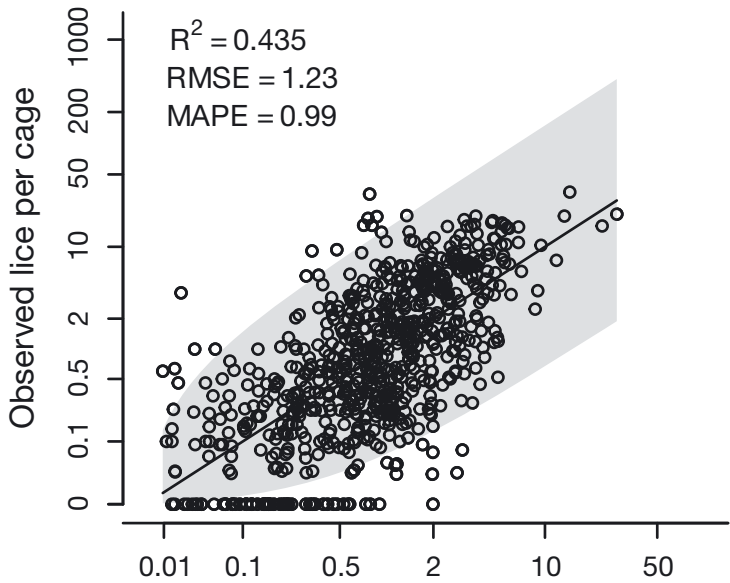

e. Best model with salinity $(\mathrm{H} 1-\mathrm{H} 11)$

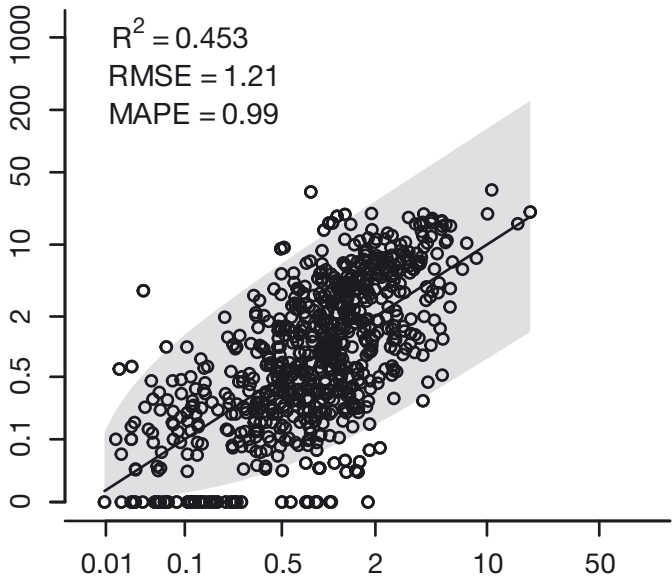

Predicted lice per cage 2012-2017 b. Baseline model

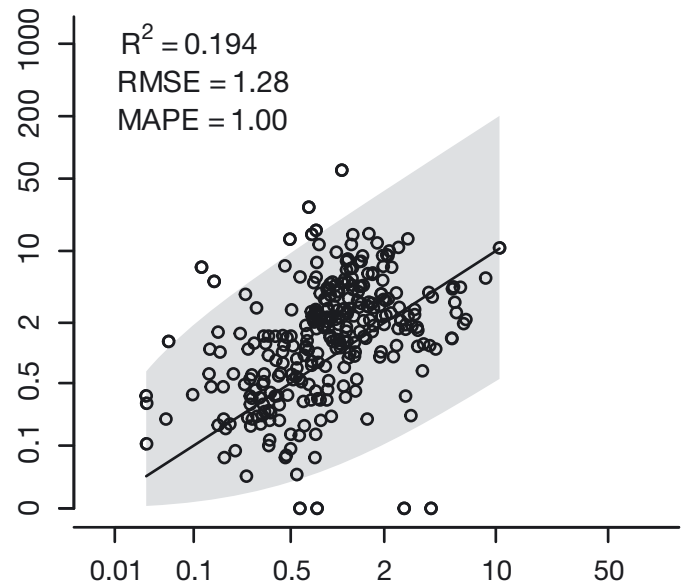

d. Best model without salinity $(\mathrm{H} 1-\mathrm{H} 9)$

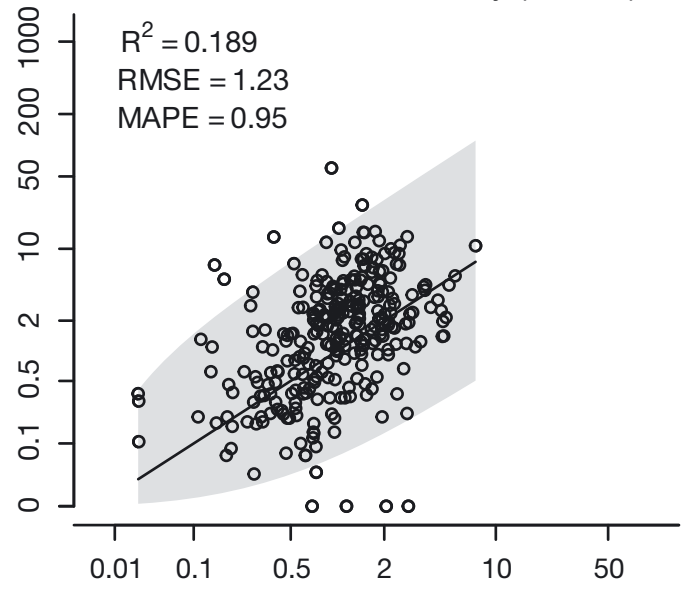

f. Best model with salinity $(\mathrm{H} 1-\mathrm{H} 11)$

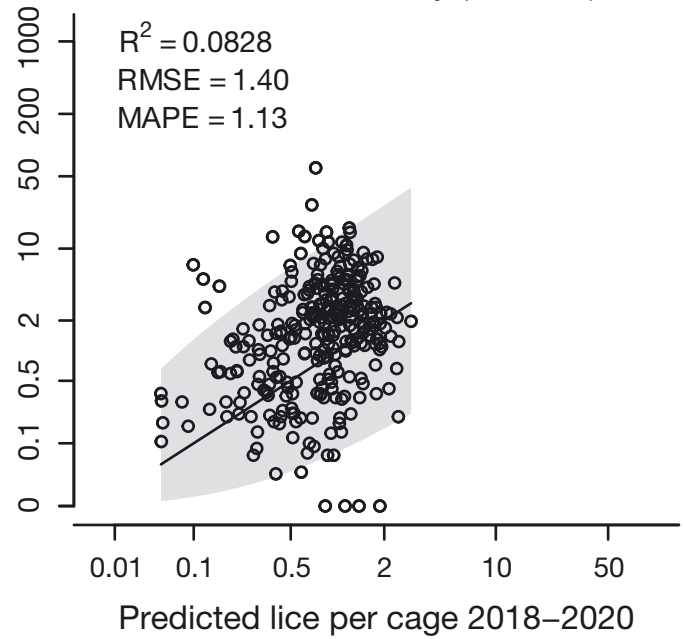

Fig. 8. Within-sample and out-of-sample predictions for alternative ways to calculate salmon lice infestation pressure. (a,b) Baseline model $_{i}(\mathrm{c}, \mathrm{d})$ best model without salinity (with H1-H9 implemented or not as indicated by asterisks in Table 1); (e,f) best model with salinity (H1-H11). The model formulation was selected using data for 2012-2017 and out-of-sample predictions were made for 2018-2020. Grey bands: $95 \%$ prediction intervals. Variance explained $\left(\mathrm{R}^{2}\right)$, root-mean-squared prediction error (RMSE) and mean absolute prediction error (MAPE) were calculated at the scale ln(lice per cage +0.033 ) 
The RMSE and MAPE of the predictions for 2018-2020 were similar to RMSE and MAPE for the test data years 2012-2017 while $\mathrm{R}^{2}$ was lower (Fig. 8). The lower $\mathrm{R}^{2}$ was a result of $38 \%$ lower between-cage variance in lice levels in 2018-2020 than in the test data years.

To investigate why predictions for 2018-2020 were not improved by accounting for salinity and the statistical temperature effect, we also fitted the model (Eqs. 9c \& 15a) to data on salinity, temperature and calculated infestation pressure only for 2018-2020. Data for these years alone showed that lice abundance was significantly $(p<0.05)$ higher than expected from the calculated infestation pressure at low salinity
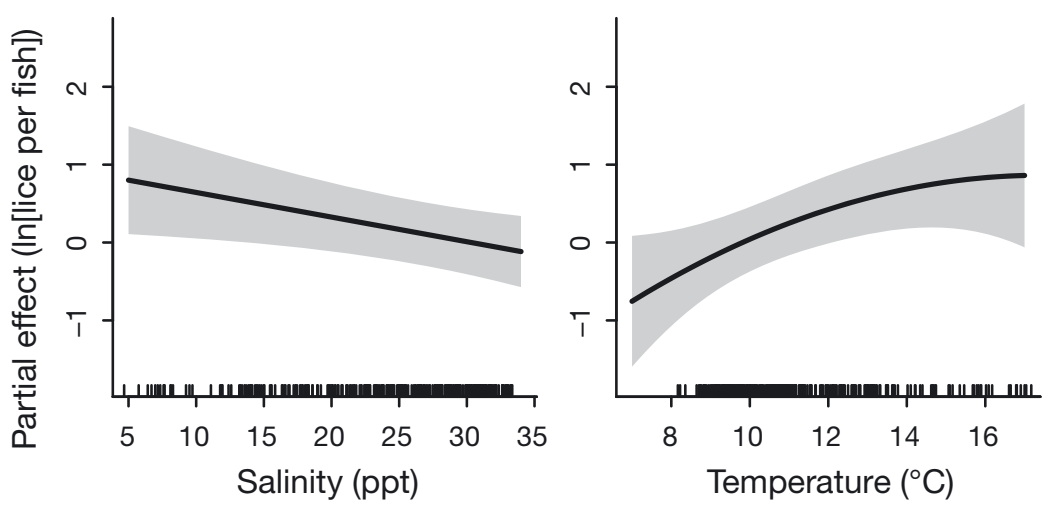

Fig. 9. Estimated additive effects of salinity and temperature on $\ln$ (lice per fish) when fitted only on data from 2018-2020. The figure shows partial effects with $95 \%$ pointwise confidence bands. The model also includes infestation pressure as a covariate, which assumes temperature-dependent production of lice larvae and temperature- and salinity-dependent infectivity. Tick marks on the $x$-axes show the locations of the data

(Fig. 9). As for the earlier years, lice abundance was significantly lower at low temperature, whereas no reduction was found at high temperature (Fig. 9). We also tested whether the low predictive power for 2018-2020 was caused by the interaction effect between temperature and salinity; the interaction model (Eq. 15b) did not provide lower RMSE or MAPE than the additive model (results not shown). The salinity and temperature ranges observed in 2018-2020 were similar to the earlier years (shown by the tick marks on the $x$-axes in Figs. $6 \& 9$ ). Sensitivity analysis suggested that errors in NorKyst800-modelled temperature and salinity may have contributed to, but seem unlikely to be the main cause of, the changing relationship between lice infestations and temperature and salinity (see Supplement).

\section{DISCUSSION}

We have provided field validation of laboratory results on how temperature and salinity influence salmon louse rates of development, reproduction, mortality and infestation and improved a model (Kristoffersen et al. 2014, 2018) for quantifying the spatial and temporal variation in salmon lice infestation pressure. The model improvements enable more precise estimation of the rate at which salmon lice from fish farms infest salmon post-smolts on their outward migration through coastal areas with high farm densities. In the following paragraphs, we discuss which factors improved the model, and why, in relation to the 12 hypotheses proposed in Section 1.

Hypothesis H1 was mostly of a technical nature and addressed how best to link the sentinel cage data to the calculated infestation pressure to estimate infestation rate. As hypothesised, we found that the abundance of salmon lice on salmon post-smolts in sentinel cage experiments was better predicted by the cumulative number of infective larvae in the experimental period than by the mean production of infective larvae during the last $2 \mathrm{wk}$ of the experiment. We note that this methodological improvement was important for comparing different methods to calculate infestation pressure, but probably of limited importance for predicting lice infestation of wild post-smolts, which either way uses infestation pressure during the entire post-smolt migration period (Kristoffersen et al. 2018).

Our results supported hypothesis H2 by showing that the predictions became more precise by using new (Aldrin et al. 2019) rather than old (Aldrin et al. 2013) estimates for how the dispersal probability of salmon lice larvae decreases with distance. The new dispersal probability function differs from the old one by decreasing faster with distance (Fig. 2), meaning that distant fish farms (e.g. $>5 \mathrm{~km}$ away) contribute somewhat less to infestation pressure than previously assumed. The new function is possibly more precise than the old one because it is based on weekly rather than monthly salmon lice counts.

Our results did not support hypothesis H3, proposing that predictions would become more precise if the mortality rate of adult (egg-bearing) female lice was reduced from 0.17 to 0.12 (Aldrin et al. 2017), the mortality of planktonic lice larvae was increased from 0.17 to 0.30 (Aldrin et al. 2017) and/or the postinfestation mortality of lice larvae was increased from 0.001 to 0.01 (Stien et al. 2005). The mortality of 
adult female lice on farmed salmon may be higher than the tested value of 0.12 , as this estimate represented the baseline mortality rate with no reported anti-lice treatment (Aldrin et al. 2017). We are not aware of estimates of adult lice mortality on farmed salmon that integrate all mortality sources, as needed for our modelling purpose. On the other hand, the mortality of planktonic lice larvae may be lower than the tested value of 0.30 , as this estimate included loss of larvae that drifted away from the farm (Aldrin et al. 2017). Predation is thought to be a main cause of mortality at this stage, as it is for other zooplankton organisms (Brooker et al. 2018). In addition, the planktonic salmon lice larvae do not feed and will die if they fail to attach to a fish host before their energy stores are used up (Johnson \& Albright 1991). We lack estimates of predation rates on salmon lice larvae, but the baseline value of 0.17 is more consistent than 0.30 with mortality rates reported for other planktonic copepods of similar size and hence sharing many of the same predators (Melle et al. 2014, Kvile et al. 2016 and references therein). Results appeared insensitive to choosing a post-infestation mortality of 0.001 or 0.01 . In summary, our results as well as the current literature thereby support that the mortality rates assumed in the baseline model remain valid best guesses.

Our results supported hypothesis H4 by showing that the predictions for 2012-2017 became more precise by calculating development time by a temperature-dependent development fraction approach (Hamre et al. 2019) rather than by assuming that the sum of egg and larval development required 126 degree-days. When testing $\mathrm{H} 4$, the development fraction approach used the functions for temperature-dependent egg and larval development times published by Stien et al. (2005). The 2 approaches predicted the same development time around $10^{\circ} \mathrm{C}$, whereas the development fraction approach implied that development takes more than 126 degree-days at temperatures lower than $10^{\circ} \mathrm{C}$ and less than 126 degree-days at temperatures higher than $10^{\circ} \mathrm{C}$ (Fig. 3c). At $5{ }^{\circ} \mathrm{C}$ the difference between approaches is around $5 \mathrm{~d}$ ( 26 degree-days), and at $15^{\circ} \mathrm{C}$ the difference between approaches is around -2 d $(-26$ degree-days). Recent studies for both eggs and larvae supported that development requires a lower number of degree-days when temperatures are high than low. For example, Hamre et al. (2019) found that the number of degree-days between egg batches decreased from 100 at $6^{\circ} \mathrm{C}$ to 72 at $18^{\circ} \mathrm{C}$, and Samsing et al. (2016) found that larval (naupliar) development time decreased from 59 degree-days at $5^{\circ} \mathrm{C}$ to
33 degree-days at $20^{\circ} \mathrm{C}$. While approximating development time by using a fixed number of degree-days may be convenient in some circumstances, our results suggest that such approximation may lead to a measurable loss in the precision of estimates of salmon lice infestation pressure. The difference in precision is small, however, and using the development fraction approach did not improve predictive power for years 2018-2020.

Our results failed to support hypothesis H5, proposing that predictions would become more precise if the function for temperature-dependent egg development time (Stien et al. 2005) was updated with new experimental data (Samsing et al. 2016, Hamre et al. 2019). The results from Hamre et al. (2019) were highly consistent with the previous function (Stien et al. 2005), while the results of Samsing et al. (2016) suggested shorter egg development time (Fig. 3a). The numbers by Hamre et al. (2019) are time between egg batches, which is a measure directly relevant for egg production rate. The egg development times of Samsing et al. (2016) were only published as supplementary data and were in vitro times to hatching of egg strings that were removed from female lice. These numbers may underestimate total egg development time, as development of egg strings and eggs prior to removal of egg strings from females is not included. Our results suggest that these numbers should not be used as estimates of total egg development time (although included in a recent review on the topic; Brooker et al. 2018).

Our results neither supported nor refuted hypothesis H6, proposing that predictions would become more precise if the function for temperature-dependent larval development time (Stien et al. 2005) was updated with new experimental data (Samsing et al. 2016) or replaced by a newly published function (Samsing et al. 2016). The updated function with reestimated parameters using old as well as new data was nearly indistinguishable from the old function, while the published function by Samsing et al. (2016) suggested slightly longer development time at the lowest temperatures considered (Fig. 3b). This difference was only distinguishable at temperatures lower than about $8^{\circ} \mathrm{C}$. Mean seawater temperatures during sentinel cage experiments ranged from $7.8-16.6^{\circ} \mathrm{C}$, with $90 \%$ of experiments conducted between 8.9 and $14.5^{\circ} \mathrm{C}$. We therefore lacked data from cold temperatures, when the functions differ. We note that the function of Stien et al. (2005) applies for the experimental temperature range of $2-19^{\circ} \mathrm{C}$ and that of Samsing et al. (2016) for $5-20^{\circ} \mathrm{C}$, with the combined function for $2-20^{\circ} \mathrm{C}$. The updated function (Eq. 11b), 
therefore, has the lowest risk of extrapolation when applied to a wide temperature range.

Our results provided weak support for hypothesis H7, proposing that predictions would become more precise if we accounted for temperature-dependent egg batch size (Samsing et al. 2016), and for hypothesis H8, proposing that predictions would become more precise if we accounted for temperature-dependent egg viability (Samsing et al. 2016). Accounting for these effects of temperature slightly improved predictions of lice infestations for 2012-2017, whereas the accuracy for 2018-2020 remained practically unchanged. The modelled relationship between temperature and egg production rate depended on the relationships assumed between temperature and 3 factors: egg batch release rate (an inverse function of egg development time), egg batch size and egg viability. Temperature effects on egg batch release rate dominated over the effects on the other 2 factors, with egg production rate increasing with increasing temperatures for all models considered, only with different functional forms (Fig. $4 \mathrm{a}-\mathrm{C}$ ). Our results suggest that the accuracy of predictions of salmon lice infestation pressure depends at most weakly on the assumptions made for temperature effects on egg batch size and egg viability, at least within the temperature range we have data for. Accounting for temperature effects on egg batch size (Samsing et al. 2016) may nonetheless be important to avoid overestimating infestation pressure at very high or low temperatures (Fig. 4c). Temperature-dependent egg batch size is consistent with field studies showing that egg batch size decreased from winter, with temperatures around $4^{\circ} \mathrm{C}$, to summer, with temperatures around $14-15^{\circ} \mathrm{C}$ (Ritchie et al. 1993, Gravil 1996). Accounting for temperature effects on egg viability has very little effect on the temperature-egg production function (Fig. 4c).

Our results provided some support for hypothesis H9, proposing that predictions would become more precise if temperature-dependent infectivity was accounted for (Tucker et al. 2000, Samsing et al. 2016, Dalvin et al. 2020, Skern-Mauritzen et al. 2020). Applying this correction improved predictions of lice infestations for 2012-2017, whereas the accuracy for 2018-2020 remained unchanged. Both the tested functions, i.e. temperature-dependent infectivity (Eq. 13a) and temperature- and time-dependent infectivity (Eq. 13b), improved predictions for 20122017, and results did not clearly favour one function over the other. It was therefore not possible to determine whether the time-dependence in infectivity estimated by Skern-Mauritzen et al. (2020) was supported by the data.
Our results did not support hypothesis H10, proposing that predictions would become more accurate by accounting for salinity-dependent egg viability (Johnson \& Albright 1991). Specifically, we found that such a correction improved predictions for 20122017, but not when salinity-dependent infectivity was accounted for. On the other hand, correcting for salinity-dependent infectivity improved predictions whether or not salinity-dependent egg viability was accounted for. Therefore, we think that the salinity correction of egg viability improved predictions because the correction acted as a proxy for correlated salinity effects later in life. Note that the correction for salinity-dependent egg viability can be questioned, as the function was calculated for salinity controlled in laboratory experiments (Samsing et al. 2016), whereas we applied the correction based on sea surface salinity, which may differ from the ambient salinity experienced by the salmon lice. As salmon hosts are distributed in the water column and salinity generally increases with depth, most adult, egg-bearing salmon lice probably experienced higher salinity than we assumed. A more realistic representation of the ambient salinity experienced by the egg-bearing salmon lice would require the use of depth-resolved salinity data as well as information about the vertical behaviour of lice-infested farmed salmon in salinity gradients.

The results for 2012-2017 provided clear support for hypothesis H11, proposing that predictions would become more precise by accounting for salinitydependent infectivity (Tucker et al. 2000, Bricknell et al. 2006). While this correction was parameterized based on experimental results on infestation success (Tucker et al. 2000, Bricknell et al. 2006), several mechanisms could contribute to low lice levels at low salinities. Experimental studies have shown that low salinity reduces not only infestation rate, but also survival of free-swimming Lepeophtheirus salmonis larvae (Gravil 1996, Bricknell et al. 2006) and post-infestation survival of the lice on the salmon (Bricknell et al. 2006). Furthermore, low-saline upper water layers may form a refuge for salmon post-smolts from lice larvae, as lice larvae actively avoid low salinity in surface layers by staying deeper in the water column (Bricknell et al. 2006, Crosbie et al. 2019). Surprisingly, predictions for 2018-2020 became worse by applying the correction. The statistical model fitted to data for 2018-2020 showed a statistically positive salinity effect that effectively cancelled out the correction for salinity-dependent infectivity, meaning that for these years, there was no association between salinity and lice levels. Several explanations 
are possible for this finding, including data issues and time-varying correlations between salinity and factors that influence lice levels. We will return to this issue in the discussion of Hypothesis H12.

The statistical testing for additional effects of salinity and temperature (H12) showed no effect of salinity and a cubic effect of temperature for 2012-2017. Hence, for these years, the correction for salinitydependent infectivity seemed to fully account for the relationship between salinity and lice levels. The calculated infestation pressure seemed to overestimate infestation levels at low as well as high temperatures, however. Temperature influences salmon lice infestation dynamics through a number of processes, and erroneous model assumptions for several of these processes could explain such a pattern. Temperature could, for example, have a more strongly domeshaped effect on infectivity than assumed (as indicated by the results of Samsing et al. 2016, see our Fig. 5a). Temperature could also have other effects than those modelled, such as through mortality rates of salmon lice. Especially the planktonic salmon lice larvae are likely to be exposed to spatial and temporal variation in predation mortality, as predation pressure depends on time-varying and potentially temperature-dependent factors such as plankton community composition and activity levels of predators and prey (Brooker et al. 2018). We lack data on how predation on salmon lice larvae varies in space and time, but note that mortality rates of eggs and nauplii of the ubiquitous copepod Calanus finmarchicus scale positively with temperature, with higher mortality in warm than cold periods and locations in the Northwest Atlantic (Plourde et al. 2009). Key biotic factors that correlated with mortality were abundances of adult C. finmarchicus and phytoplankton, suggesting that adults of $C$. finmarchicus ate copepod eggs and nauplii at the highest rate when the concentration of their main prey, phytoplankton, was low (Plourde et al. 2009).

Correcting for the statistical association with temperature led to worse predictions for 2018-2020, showing that the relationship with temperature had changed. This mirrors the finding for salinity, which also showed a change in the relationship with lice infestations. These changes may reflect inter-annual changes in the relative importance of the many direct and indirect mechanisms by which salinity and temperature affect salmon lice abundance. Similarly, correlations between temperature and fish recruitment, which also operate through a number of direct and indirect mechanisms, are often non-stationary (Ottersen et al. 2013). If, for example, the abundance of a predator on lice larvae in the plankton varies between years and this predator is associated with a particular water mass (e.g. warm and saline waters), the correlations of temperature and salinity with lice predation mortality will vary. The effect of sea surface salinity may further depend on the steepness and depth of the halocline in relation to the depth of the salmon (here, around $1 \mathrm{~m}$ ), as lice larvae tend to aggregate at or immediately below the halocline (Bricknell et al. 2006, Crosbie et al. 2019). A weaker effect of salinity in recent years could hypothetically be caused by the freshwater layer being thinner than in earlier years, as, for a given sea surface salinity, a thin freshwater layer would reduce host-parasite contact rates less than what a thick freshwater layer would do. The depth of the thermocline does not seem to affect the depth of salmon lice during the infective larval stage (Crosbie et al. 2020) but could nonetheless influence our results, as a thermocline shallower than $3 \mathrm{~m}$ would cause a discrepancy between the modelled $3 \mathrm{~m}$ temperature and temperature at the $1 \mathrm{~m}$ depth of the salmon. We lack data for how the depths of the halocline and thermocline varied between years. The available observation data suggested, however, a strong association between temperatures at 1 and $3 \mathrm{~m}$, and, moreover, that errors in modelled temperature and salinity were probably not large enough to explain the discrepancy between modelled and observed lice levels at low salinity and high temperature in 2018-2020 (see the Supplement). There is, nonetheless, a risk that the statistical associations were spurious or influenced by inaccuracies in the data. We conclude that our results do not support using the statistical relationships in predictive modelling, and point to a knowledge gap in our understanding of how temperature and salinity indirectly or directly affect salmon lice dynamics.

We found that the effects of salinity and temperature were synergistic: the negative effect of the 2 stressors in combination was stronger than the sum of their individual effects. The negative effect of suboptimal temperature was stronger when salinity was low (e.g. 20-30 ppt) than high (34 ppt, i.e. fullstrength seawater). In comparison, the majority of combined effects of multiple abiotic stressors on marine embryos and larvae have been reported to be synergistic (Przeslawski et al. 2015). However, temperature and salinity appear to have compensatory effects on larval survival of the sea louse Caligus rogercresseyi, with temperature only influencing survival when salinity is favourable (salinity > 20 ppt; Montory et al. 2018). The possible mechanisms behind the apparent synergistic effects in L. salmonis 
remain unclear, and accounting for these effects did not improve the precision of our model. We consider it premature to incorporate this possible synergistic effect in models of salmon lice infestation of wild salmon post-smolts, but urge experiments that quantify combined effects of salinity and temperature on lice larval survival and infectivity.

While these results show that the modelled infestation pressure explains a large part of the observed variation in lice counts in sentinel cage experiments, there are some caveats. Firstly, it is uncertain how well the experiments with salmon placed in stationary sentinel cages represent actively swimming wild salmon post-smolts (see Kristoffersen et al. 2018). Experiments with towed cages and analyses of data from trawl-caught post-smolts of wild salmon may potentially throw light on this issue in the future. Secondly, it was not always clear which reductions in unexplained variance truly reflected real improvements in the model's predictive power and which differences arose just by chance. This problem was underlined by the out-of-sample predictions for 20182020, which showed that several of the model formulations performed similarly well. Therefore, the small differences in model performance between some of the alternative formulations should be interpreted with caution. Finally, we acknowledge the need for further model improvement to reduce uncertainty in model predictions. Reduced uncertainty can be obtained by improved input data quality, as, for example, harvesting cages where salmon are stored before slaughtering as well as farms the last $2 \mathrm{wk}$ before slaughter are currently not required to report lice numbers (Ministry of Trade, Industry and Fisheries 2012). More precise temperature and salinity data at relevant depths can also reduce the uncertainty, with, for example, farm-specific temperature measurements at more depths than $3 \mathrm{~m}$ allowing for a more realistic representation of temperatures of egg-bearing female lice (Oppedal et al. 2011), and higher spatial resolution of the ocean model in topographically complex areas improving the accuracy of modelled temperature and salinity further (Asplin et al. 2020). Reduced uncertainty can also potentially be obtained through new knowledge about key model parameters such as natural mortality rates, or through reformulating the model, for example to take into account ocean currents. To estimate mortality of migrating wild salmon post-smolts, there are also other important sources of uncertainty, such as incomplete knowledge about migration timing and routes and incomplete knowledge about what effect a given lice load has on the mortality of the juvenile salmon (see
Kristoffersen et al. 2018 and Vollset 2019 for sensitivity analyses for the role of some of these factors).

\section{CONCLUSIONS}

We have reviewed and synthesized studies on key processes in salmon lice infestation dynamics, with a focus on experimental investigations of salinity and temperature effects. The relevance of the new findings for predicting lice infestations on salmon postsmolts in the sea was assessed by a statistical-mechanistic modelling approach. Using this modelling approach, the spatial and temporal variation in infestation pressure was mechanistically modelled based on (1) extensive monitoring data on female salmon lice in Norwegian fish farms and (2) functions for potentially temperature- and salinity-dependent salmon lice egg production, development, mortality and infectivity. A statistical model element linked the calculated infestation pressure to observations of salmon lice infestations on salmon post-smolts in experimental cages. We found that predictions of salmon lice infestations for 2012-2017 were improved by a series of changes in model formulation, most notably by taking into account salinity- and temperaturedependent infectivity and by a change from a degree-days approximation of development time to a fractional development approach. We did not find statistical support for changing the function for temperature-dependent egg development time, stagedependent mortality rates or for taking into account salinity-dependent egg viability. Results were inconclusive regarding the alternative functions for temperature-dependent larval development time, egg batch size and egg viability. Results further suggested that the association between salinity and observed lice levels for 2012-2017 was well explained by the calculated infestation pressure, whereas lice levels appeared to be overestimated at both low and high temperatures. Such overestimation appeared to be accentuated at low salinity, suggesting a possibly synergistic interaction effect of sub-optimal salinity and temperature. Out-of-sample predictions for 20182020 supported that the model quantified the uncertainty realistically. However, correcting for salinitydependent infectivity or the statistical association with temperature did not improve predictions for 20182020 and point to a gap in our knowledge about the mechanisms that link temperature and salinity to salmon lice dynamics.

These results contribute to quantify and reduce the uncertainty in future estimates of the effects of fish 
farming on wild salmon populations, a matter of large societal and economic importance and considerable debate (Vollset et al. 2018). The Ministry of Trade, Industry and Fisheries in Norway recently enforced biomass reductions for open-net salmonid fish farming in parts of the coast where the salmon lice-induced mortality of wild salmon post-smolts was considered to be too high for the production to be environmentally sustainable. Model-based estimates of lice-induced mortality (Kristoffersen et al. 2018, Myksvoll et al. 2018, Sandvik et al. 2020) were important parts of the decision support, and continual development and refinement of these models is important for regulating the fish-farming industry in a way that protects wild salmon populations while providing predictable regulatory conditions for fish farmers. Our study contributes to this end by synthesizing experimental results from multiple studies and testing the relevance of these findings for salmon lice in the sea, to make the best use of the available knowledge.

Acknowledgements. We thank Jon Albretsen from the Institute of Marine Research (IMR) for extracting and sharing data from the NorKyst800 model, Sussie Dalvin, IMR, for providing infestation success data, and Ørjan Karlsen, IMR, and the Norwegian Marine Data Centre for providing data from the sentinel cage experiments. This research did not receive any specific grant from funding agencies in the public, commercial or not-for-profit sectors.

\section{LITERATURE CITED}

Aldrin M, Storvik B, Kristoffersen AB, Jansen PA (2013) Space-time modelling of the spread of salmon lice between and within Norwegian marine salmon farms. PLOS ONE 8:e64039

Aldrin M, Huseby RB, Stien A, Grøntvedt RN, Viljugrein H, Jansen PA (2017) A stage-structured Bayesian hierarchical model for salmon lice populations at individual salmon farms - estimated from multiple farm data sets. Ecol Modell 359:333-348

Aldrin M, Jansen PA, Stryhn H (2019) A partly stage-structured model for the abundance of salmon lice in salmonid farms. Epidemics 26:9-22

Asplin L, Albretsen J, Johnsen IA, Sandvik AD (2020) The hydrodynamic foundation for salmon lice dispersion modeling along the Norwegian coast. Ocean Dyn 70: 1151-1167

Bates D, Mächler M, Bolker B, Walker S (2015) Fitting linear mixed-effects models using lme4. J Stat Softw 67:1-48

Beldring S, Engeland K, Roald LA, Sælthun NR, Voksø A (2003) Estimation of parameters in a distributed precipitation-runoff model for Norway. Hydrol Earth Syst Sci 7: 304-316

Bjørn PA, Sivertsgard R, Finstad B, Nilsen R, Serra-Llinares RM, Kristoffersen R (2011) Area protection may reduce salmon louse infection risk to wild salmonids. Aquacult Environ Interact 1:233-244

Boxaspen K, Næss T (2000) Development of eggs and the planktonic stages of salmon lice (Lepeophtheirus salmonis) at low temperatures. Contrib Zool 69:51-55

* Bricknell IR, Dalesman SJ, O'Shea B, Pert CC, Luntz AJM (2006) Effect of environmental salinity on sea lice Lepeophtheirus salmonis settlement success. Dis Aquat Org 71:201-212

* Brooker AJ, Skern-Mauritzen R, Bron JE (2018) Production, mortality, and infectivity of planktonic larval sea lice, Lepeophtheirus salmonis (Kroyer, 1837): current knowledge and implications for epidemiological modelling. ICES J Mar Sci 75:1214-1234

* Crosbie T, Wright DW, Oppedal F, Johnsen IA, Samsing F, Dempster T (2019) Effects of step salinity gradients on salmon lice larvae behaviour and dispersal. Aquacult Environ Interact 11:181-190

Crosbie T, Wright DW, Oppedal F, Dalvin S, Myksvoll MS, Dempster T (2020) Impact of thermoclines on the vertical distribution of salmon lice larvae. Aquacult Environ Interact 12:1-10

* Dalsøren SB, Albretsen J, Asplin L (2020) New validation method for hydrodynamic fjord models applied in the Hardangerfjord, Norway. Estuar Coast Shelf Sci 246: 107028

* Dalvin S, Are Hamre L, Skern-Mauritzen R, Vågseth T, Stien L, Oppedal F, Bui S (2020) The effect of temperature on ability of Lepeophtheirus salmonis to infect and persist on Atlantic salmon. J Fish Dis 43:1519-1529

* Eisenhauer L, Solvang T, Alver M, Krause DF, Hagemann A (2020) Dispersal of salmon lice (Lepeophtheirus salmonis Krøyer, 1837) egg strings from open-cage salmon farming: a neglected source for infestation dynamics. Aquacult Res 51:4595-4601

FAO (2019) FAO yearbook. Fishery and aquaculture statistics 2017. FAO, Rome

Gravil HR (1996) Studies on the biology and ecology of the free swimming larval stages of Lepeophtheirus salmonis (Krøyer, 1838) and Caligus elongatus Nordmann, 1832 (Copepoda: Caligidae). PhD dissertation, University of Stirling

*Grimnes A, Jakobsen PJ (1996) The physiological effects of salmon lice infection on post-smolt of Atlantic salmon. J Fish Biol 48:1179-1194

*Hamre LA, Bui S, Oppedal F, Skern-Mauritzen R, Dalvin S (2019) Development of the salmon louse Lepeophtheirus salmonis parasitic stages in temperatures ranging from 3 to $24^{\circ} \mathrm{C}$. Aquacult Environ Interact 11:429-443

*Heuch PA, Mo TA (2001) A model of salmon louse production in Norway: effects of increasing salmon production and public management measures. Dis Aquat Org 45: 145-152

KHeuch PA, Nordhagen JR, Schram TA (2000) Egg production in the salmon louse [Lepeophtheirus salmonis (Krøyer)] in relation to origin and water temperature. Aquacult Res 31:805-814

Jansen PA, Kristoffersen AB, Viljugrein H, Jimenez D, Aldrin M, Stien A (2012) Sea lice as a density-dependent constraint to salmonid farming. Proc R Soc B 279: 2330-2338

Johannessen A (1977) Early stages of Lepeophtheirus salmonis (Copepoda, Caligidae). Sarsia 63:169-176

Johansen LH, Jensen I, Mikkelsen H, Bjørn PA, Jansen PA, Bergh $\varnothing$ (2011) Disease interaction and pathogens exchange between wild and farmed fish populations with special reference to Norway. Aquaculture 315: 167-186 
Johnson SC, Albright LJ (1991) Development, growth, and survival of Lepephtheirus salmonis (Copepoda: Caligidae) under laboratory conditions. J Mar Biol Assoc UK 71:425-436

Kristoffersen AB, Jimenez D, Viljugrein H, Grøntvedt R, Stien A, Jansen PA (2014) Large scale modelling of salmon lice (Lepeophtheirus salmonis) infection pressure based on lice monitoring data from Norwegian salmonid farms. Epidemics 9:31-39

Kristoffersen AB, Qviller L, Helgesen KO, Vollset KW, Viljugrein H, Jansen PA (2018) Quantitative risk assessment of salmon louse-induced mortality of seaward-migrating post-smolt Atlantic salmon. Epidemics 23:19-33

Krkošek M, Morton A, Volpe JP, Lewis MA (2009) Sea lice and salmon population dynamics: effects of exposure time for migratory fish. Proc R Soc B 276:2819-2828

Kvile KØ, Stige LC, Prokopchuk I, Langangen Ø (2016) A statistical regression approach to estimate zooplankton mortality from spatiotemporal survey data. J Plankton Res 38:624-635

Melle W, Runge J, Head E, Plourde S and others (2014) The North Atlantic Ocean as habitat for Calanus finmarchicus: environmental factors and life history traits. Prog Oceanogr 129:244-284

Ministry of Trade, Industry and Fisheries (2012) Forskrift om bekjempelse av lakselus i akvakulturanlegg (Regulation on control of salmon lice in aquaculture). Nærings- og fiskeridepartementet. https://lovdata.no/dokument/SF/ forskrift/2012-12-05-1140 (accessed 24 February 2020)

Ministry of Trade, Industry and Fisheries (2015) Forutsigbar og miljømessig bærekraftig vekst i norsk lakse- og ørretoppdrett (Predictable and environmentally sustainable growth in Norwegian salmon and trout production). Nærings- og fiskeridepartementet. https://www. regjeringen.no/no/dokumenter/meld.-st.-16-2014-2015/ id2401865/ (accessed 30 September 2019)

Montory JA, Cumillaf JP, Cubillos VM, Paschke K, Urbina MA, Gebauer P (2018) Early development of the ectoparasite Caligus rogercresseyi under combined salinity and temperature gradients. Aquaculture 486:68-74

Myksvoll MS, Sandvik AD, Albretsen J, Asplin L and others (2018) Evaluation of a national operational salmon lice monitoring system - from physics to fish. PLOS ONE 13: e0201338

Oppedal F, Dempster T, Stien LH (2011) Environmental drivers of Atlantic salmon behaviour in sea-cages: a review. Aquaculture 311:1-18

Ottersen G, Stige LC, Durant JM, Chan KS, Rouyer TA, Drinkwater KF, Stenseth NC (2013) Temporal shifts in recruitment dynamics of North Atlantic fish stocks: effects of spawning stock and temperature. Mar Ecol Prog Ser 480:205-225

Pike AW, Wadsworth SL (1999) Sealice on salmonids: their biology and control. Adv Parasitol 44:233-337

* Plourde S, Pepin P, Head EJH (2009) Long-term seasonal and spatial patterns in mortality and survival of Calanus finmarchicus across the Atlantic Zone Monitoring Programme region, Northwest Atlantic. ICES J Mar Sci 66: 1942-1958

"Przeslawski R, Byrne M, Mellin C (2015) A review and meta-analysis of the effects of multiple abiotic stressors

Editorial responsibility: Kate S. Hutson,

Nelson, New Zealand

Reviewed by: E. Mironova, S. Murray and

1 anonymous referee on marine embryos and larvae. Glob Change Biol 21: 2122-2140

R Core Team (2019) R: a language and environment for statistical computing. R Foundation for Statistical Computing, Vienna

Ritchie G, Mordue AJ, Pike AW, Rae GH (1993) The reproductive output of Lepeophtheirus salmonis adult females in relation to seasonal variability of temperature and photoperiod. In: Boxshall GA, Defaye D (eds) Pathogens of wild and farmed fish. Ellis Horwood, New York, NY, p 153-165

* Samsing F, Oppedal F, Dalvin S, Johnsen I, Vågseth T, Dempster T (2016) Salmon lice (Lepeophtheirus salmonis) development times, body size, and reproductive outputs follow universal models of temperature dependence. Can J Fish Aquat Sci 73:1841-1851

* Sandvik AD, Johnsen IA, Myksvoll MS, Sævik PN, Skogen MD (2020) Prediction of the salmon lice infestation pressure in a Norwegian fjord. ICES J Mar Sci 77:746-756

Skern-Mauritzen R, Sissener NH, Sandvik AD, Meier S and others (2020) Parasite development affect dispersal dynamics; infectivity, activity and energetic status in cohorts of salmon louse copepodids. J Exp Mar Biol Ecol 530-531:151429

Stien A, Bjørn PA, Heuch PA, Elston DA (2005) Population dynamics of salmon lice Lepeophtheirus salmonis on Atlantic salmon and sea trout. Mar Ecol Prog Ser 290: 263-275

* Thorstad EB, Todd CD, Uglem I, Bjørn PA and others (2015) Effects of salmon lice Lepeophtheirus salmonis on wild sea trout Salmo trutta-a literature review. Aquacult Environ Interact 7:91-113

* Tucker CS, Sommerville C, Wootten R (2000) The effect of temperature and salinity on the settlement and survival of copepodids of Lepeophtheirus salmonis (Krøyer, 1837) on Atlantic salmon, Salmo salar L. J Fish Dis 23:309-320

Tucker CS, Norman R, Shinn AP, Bron JE, Sommerville C, Wootten R (2002) A single cohort time delay model of the life-cycle of the salmon louse Lepeophtheirus salmonis on Atlantic salmon Salmo salar. Fish Pathol 37:107-118

*Vollset KW (2019) Parasite induced mortality is context dependent in Atlantic salmon: insights from an individual-based model. Sci Rep 9:17377

Vollset KW, Dohoo I, Karlsen Ø, Halttunen E and others (2018) Disentangling the role of sea lice on the marine survival of Atlantic salmon. ICES J Mar Sci 75:50-60

* Vollset KW, Nilsen F, Ellingsen I, Finstad B and others (2019) Vurdering av lakselusindusert villfiskdødelighet per produksjonsområde i 2019 (Evaluation of salmon lice induced mortality of wild fish per production area in 2019). Report from the Norwegian expert group for the assessment of salmon lice effects (ekspertgruppe for vurdering av lusepåvirkning). https://www.regjeringen.no/ globalassets/departementene/nfd/dokumenter/rapporter/ ekspertgruppe-rapport_2019.pdf (accessed 2 June 2020)

Wood SN (2017) Generalized additive models: an introduction with R. Chapman \& Hall/CRC, Boca Raton, FL

Wootten R, Smith JW, Needham EA (1982) Aspects of the biology of the parasitic copepods Lepeophtheirus salmonis and Caligus elongatus on farmed salmonids, and their treatment. Proc R Soc Edinb B Biol Sci 81:185-197

Submitted: January 5, 2021

Accepted: June 1, 2021

Proofs received from author(s): August 23, 2021 